\title{
Is Business Process Management (BPM) Ready for Ambidexterity? Conceptualization, Implementation Guidelines and Research Agenda
}

\author{
Tomasz Helbin * and Amy Van Looy \\ Department of Business Informatics and Operations Management, Ghent University, 9000 Ghent, Belgium; \\ amy.vanlooy@ugent.be \\ * Correspondence: tomasz.helbin@ugent.be
}

check for updates

Citation: Helbin, T.; Van Looy, A. Is Business Process Management (BPM) Ready for Ambidexterity? Conceptualization, Implementation Guidelines and Research Agenda. Sustainability 2021, 13, 1906. https://doi.org/10.3390/su13041906

Academic Editors: Miloš Hitka and Katarína Stachová

Received: 31 December 2020

Accepted: 4 February 2021

Published: 10 February 2021

Publisher's Note: MDPI stays neutral with regard to jurisdictional claims in published maps and institutional affiliations.

Copyright: (c) 2021 by the authors. Licensee MDPI, Basel, Switzerland. This article is an open access article distributed under the terms and conditions of the Creative Commons Attribution (CC BY) license (https:// creativecommons.org/licenses/by/ $4.0 /)$.

\begin{abstract}
Business Process Management ambidexterity is a nascent concept providing a philosophy and framework for organizations to radically innovate their business processes, while maintaining their capabilities in process efficiency and operational excellence. Considering the novelty of this topic, there is not yet an agreed conceptualization of the term, nor a consolidated view on related implementation guidelines. We aim to address this research gap through a Systematic Literature Review, where we provide a dual conceptualization that focuses on (1) the equilibrium balance between explorative and exploitative processes, as well as (2) the organizational capability to support exploration and exploitation. Based on this conceptualization, we provide consolidated guidelines for practitioners, including decision steps, followed by a research agenda in order to let this promising domain further advance.
\end{abstract}

Keywords: Business Process Management; organizational ambidexterity; exploratory processes

\section{Introduction}

Digital innovation is increasingly driven by the SMACIT (i.e., social, mobile, analytics, cloud and Internet of things) technologies for reengineering, disrupting, transforming and sometimes obliterating business models and business processes [1,2]. In response, the discipline of Business Process Management (BPM) has aimed to address these transformative developments through a broad reflection on how to integrate radical, disruptive innovation into its practices, while maintaining its capabilities in efficiency and operational excellence [3]. The resulting so-called ambidextrous tension is the topic of this research paper, which intends to better translate the notion of organizational ambidexterity $(\mathrm{OA})$ to the BPM discipline. BMP ambidexterity also plays a critical role in sustainability research, being on the one hand an enabler for environmentally sustainable IT, so-called green IT [4], and on the other hand supporting financial sustainability of organizations (e.g., operational excellence in terms of efficiency, effectiveness and quality) through times of market turbulence and digital disruption $[5,6]$.

Researchers argued that BPM has mainly promoted incremental process improvement rather than the radical, disruptive process innovation [7]. However, as we will showcase in our study, this has recently changed due to the greater attention given in the BPM research domain to disruption, exploration and paradigm-shifting innovation [8]. Nevertheless, major gaps still exist in the literature, particularly in the field of conceptualization of the domain at the crossroads of BPM and OA [9,10], as well the implementation guidelines, which are of critical importance for practitioners in the current market climate.

For this purpose, our main research question is: What is the state of research on ambidexterity in the BPM discipline? We selected the research method of a Systematic Literature Review (SLR) as a rigorous and comprehensive manner to collect and assess relevant data [11]. The main contribution of this research is providing a common conceptualization of BPM ambidexterity, and an in-depth analysis of the extant guidance in 
academic literature on its implementation for practitioners. As such, this article is beneficial for both scholars and managers.

The paper is structured as follows. Section 2 provides an overview of the theoretical frameworks used to evaluate the current body of knowledge. Next, Section 3 describes the methodology that was followed for conducing our SLR. Section 4 provides a detailed overview of the findings. The paper is concluded with Section 5 , covering a discussion on the main results and a research agenda.

\section{Theoretical Background}

\subsection{Organizational Ambidexterity}

Organizational ambidexterity $(\mathrm{OA})$ is defined as "the ability of an organization to both explore and exploit-to compete in mature technologies and markets where efficiency, control, and incremental improvement are prized and to also compete in new technologies and markets where flexibility, autonomy, and experimentation are needed" [3] (p. 2). OA helps decide whether the "present should be hedged against the future" [4] (p. 116), encapsulating the tension between stability and adaptability [12].

The tension between these two forces (i.e., exploitation and exploration) has received significant attention in academia in the last 20 years [13], and major effort has been put into proposing strategies for delivering ambidexterity in an organization: either by separating the two types of activities from each other (i.e., through structural separation in an organization, or through temporal separation by performing the activities at distinct times), or through contextual integration of these activities in the same team or structural entity [14]. For the purpose of this paper, we will be referring to the typology of ambidexterity types provided by [15]: (1) structural ambidexterity (i.e., when referring to structural of temporal isolation), and (2) contextual ambidexterity (i.e., when both exploration and exploration are carried out by the same team or employee).

Additionally, ample proof has been provided on both the impact of organizational ambidexterity for firms' performance [16,17], and the necessity of implementing OA for organizations' survival in the context of the digitalization. More recently, the tension in ambidexterity has been conceptualized as a self-reinforcing paradox, expected to fuel virtual cycles of innovation $[18,19]$.

There are several antecedents of OA. One of the main dimensions is organizational learning (i.e., knowledge acquisition by actors who can influence an organization) [20], and more specifically absorptive capacity (i.e., the capability of an organization to identify, assimilate and commercialize external knowledge) [21]. This is closely related to the conceptualization of $\mathrm{OA}$ as a dynamic capability [22] (i.e., the ability of an organization to succeed in a turbulent context due to their ability to reallocate their resources [23]). As such, the latter positions OA as a resource in the resource-based view (RBV) of an organization [24]. In this context, ref. [25] "unpack" the construct of OA as (1) the balancing dimension of exploitation-exploration, and (2) the combined magnitude of the ambidexterity, which corresponds to the capability view.

Despite this broad interest in the ambidexterity topic, there are still major research gaps in terms of the agency and mechanisms of OA, research at the business process level, longitudinal studies on the evolution of OA, and the managerial guidelines on implementation of OA in order to deliver true value to the organization [26]. This paper aims to explore the topic of BPM ambidexterity, considering that business processes are one of the key enablers of OA [15], and are considered as a major research gap in that field.

\subsection{From Business Process Management (BPM) to BPM Ambidexterity}

BPM is a widely deployed and mature discipline, which can be defined as "the art and science of overseeing how work is performed in an organization to ensure consistent outcomes and to take advantage of improvement opportunities" [6] (p. 1). A key concept in BPM is the process lifecycle for systematizing the implementation and management of a given process in an organization. From this perspective, ref. [27] provided a holistic 
capability model by complementing the process lifecycle capabilities (i.e., (1) modelling, (2) deploying, (3) optimizing and (4) managing) with the organizational capabilities enabling BPM, referred to as Business Process Orientation (BPO) (i.e., (5) structure and (6) culture). This framework will be used in the next sections to structure the critical capability areas of ambidextrous BPM. We have selected this framework for our SLR because it supplements the BPM lifecycle with underlying management theories, and it was validated by 69 process-oriented maturity models. It was also one of the most comprehensive models we observed in the BPM literature, and thus serving as a proper starting point for our BPM ambidexterity work.

Similar to OA, BPM can be conceptualized as a dynamic capability, reflecting the organizations' ability to model, deploy, optimize and manage processes in order to address the organizations' changing external environment [28]. BPM programs need to be contextaware in order to deliver business value for an organization [29], which becomes even more critical in the context of rapid digitalization. The relationship of BPM with digital innovation is, however, of intense debate in the academia [30,31]. Several researchers claimed that, despite BPM's roots in the radical Business Process Reengineering of the 1990s [32], the discipline has focused in the recent decades on process control and optimization rather than disruption. Already in the beginning of this century, researchers reported on the fact that large companies were less able to react to digital disruption and adapt their BPM practices to disruptive technologies due to inertia, lack of incentives or value associated with the new technological opportunities [33]. On the other hand, BPM is arguably able to leverage the latest digital technologies in a more explorative pattern, as for example is the case with robotic process automation [34].

For this reason, researchers have started advocating the need to expand the scope of BPM from process control and exploitation, to also include exploration and radical innovation [35]. This new concept of BPM ambidexterity is the topic of this Systematic Literature Review, in order to acquire a better understanding and to guide future research.

\section{Methodology}

Systematic Literature Review (SLR) is a relatively novel type of literature review based on rigorous methods to collect and appraise data qualitatively and quantitatively [36]. Reference [11] argued that, while SLRs have limitations, they are beneficial when conducted for specific research questions and a clearly delimited topic. This applies to our research, which focuses on the novel term of BPM ambidexterity with defined review questions (Table 1).

Based on the protocol in Table 1, the review of the literature sample consisted of three steps: (1) a search query of the selected terms in the chosen databases, (2) content screening of titles and abstracts, concluded with (3) a complete analysis of the selected sample of papers. The final literature sample consisted of 71 papers. Each of the papers received a unique identifier $P x x$, and is available in the Appendix A. The three steps of the SLR process are visualized in Figure 1.

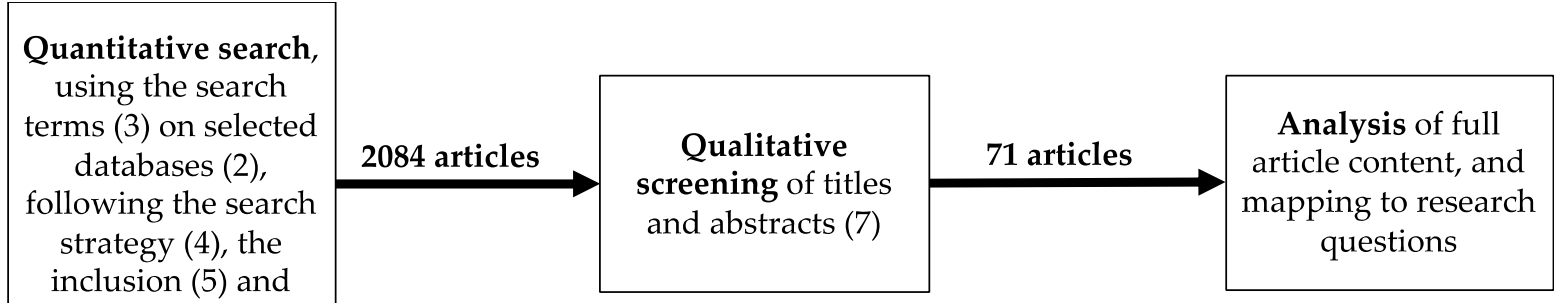

Figure 1. The three steps of the Systematic Literature Review (SLR) process. 
Table 1. SLR protocol.

\begin{tabular}{ll}
\hline \multicolumn{1}{c}{ SLR Protocol Elements } & \multicolumn{1}{c}{ Translated to Our Study } \\
\hline & What is the state of research on ambidexterity in the BPM discipline? \\
1/Research question & - SLR-Q1-What is the general background information about the research subject (i.e., \\
- Sublication types, research methods, country, publication year)?
\end{tabular}

The following eight academic, peer-reviewed databases were selected, as they were most relevant in the context of information system research and commonly used in SLRs [37]:

- $\quad$ ScienceDirect

- $\quad$ Emerald Insight

2/Sources searched $\quad$ - Springer Link

- IEEE Explore

- Scopus

- Web of Science

- $\quad$ AIS Electronic Library (AISeL)

The main search terms were covering process ambidexterity, as well as radical innovation, disruption and exploration in the context of BPM. Following several iterations, the following search keywords were combined, as they provided a broad and substantial sample of articles for the study:

3/Search terms

- "process *" AND "ambidext *"

- "process management" AND "radical innovation"

- "process management" AND “disruption"

- "process management" AND "exploration"

- Only peer-reviewed journals, conference papers and book articles (with the exception of 2020, where an additional $\mathrm{PhD}$ thesis was added resulting from a Google Scholar alert, providing the most recent insights into the research questions);

4/Search strategy

- No publication date limit nor sector limit;

- Filters (when available): subject area restricted to "business, management \& accounting"; "computer science"; "engineering"; "economics, econometrics \& finance";

- The search terms were contained in the articles' title, abstract or keywords.

- Include only papers containing a combination of the search terms, defined in the search queries;

- Include only papers indexed in the sources searched from all periods until the end of November

$5 /$ Inclusion criteria 2020, providing the researchers a cut-off date to start the data analysis;

- Include only papers written in English.

- Exclude articles using the keyword "process *" with a different meaning than BPM;

6/Exclusion criteria - Exclude articles using "ambidexterity" in a different meaning than the simultaneous pursuit of explorative and exploitative goals within organizations;

- $\quad$ Exclude articles without full access.

- Only peer-reviewed articles in the academic databases chosen;

- $\quad$ Following a validated and comprehensive BPM framework of [27] which was used to increase

7/Quality criteria

- Include only papers which conceptually address BPM ambidexterity, BPM radical innovation, disruption or exploratory BPM.

Note: *-was used as a wildcard symbol in the search queries.

This SLR was based on an earlier conference paper by the authors [10], which had a more limited scope in terms of research questions and sampling. This approach allowed us to iteratively expand the scope of the study with relevant new keywords and to refocus the research on other promising research questions (i.e., SLR-Q1 and SLR-Q2), which are relevant to both academia and practitioners. For instance, we extended the scope of the search keywords to also cover radical and disruptive innovations in BPM and to include papers covering explorative processes, without an explicit reference to ambidexterity. 
The four research questions applied to our SLR are listed in Table 1. SLR-Q1 served as an introduction to provide us with the general background context of the research state. Next, SLR-Q2 uncovered the basis for our understanding of this nascent concept of BPM ambidexterity, with a focus on identifying the various related research streams. The third question (SLR-Q3) aimed at understanding and translating ambidexterity in the context of BPM, based on a validated and comprehensive conceptual framework within the BPM domain [27]. This framework was chosen as it offers a consolidated view of the business process lifecycle in combination with organizational management theories. Finally, SLR-Q4 allowed us to grasp the practical aspects of disruption in BPM, and the balancing activities that are intrinsic to ambidexterity. To better scope the domain, we identified three sub-questions of this research question:

(1) How to adapt existing BPM practices to make them more explorative.

(2) How to balance explorative and exploitative BPM.

(3) What organizational changes (i.e., structure, culture) need to take place, in order to facilitate BPM ambidexterity?

The mapping of the papers to the answers of the questions is available as supplementary material, for download at this location: https:/ / www.icloud.com/iclouddrive/02Wi8 hVNTdhJP1_DxOegXKK1A\#Literature_sample.

\section{Results}

\subsection{Findings for SLR-Q1 (General Background)}

We first summarize the chronological evolution of the sampled papers, followed by their publication type and research methods applied. Afterwards, this overview presents the geographical distribution of the research centers active in BPM ambidexterity research so far.

\subsubsection{Evolution of Papers per Year, and Their Type}

As shown in Figure 2, the interest in this topic was growing over time. The peak was in 2018 due a related special issue of the Business Process Management Journal. Although the sampling of papers was finished in November 2020, the total for that final year was still lower as compared to 2018 and 2019. It has to be seen if this reflects a broader trend, or a temporary decrease. Nonetheless, the total of 2020 was still higher than all years before 2018, and therefore we expect a further increase of attention when entering a digital economy with emerging technologies taking the lead.

Furthermore, if we look at the publication type, most sampled papers were journal articles (51 papers), followed by 15 conference papers, four book articles, and one PhD thesis. We also observed a large increase in journal articles over the last 3 years, which further demonstrates the growing interest in this topic.

\subsubsection{Research Methods}

As shown in Figure 3 the most used research methods in the sample were case studies and conceptual papers (i.e., with 24 and 22 papers, respectively). This finding reflects our topic's novelty for which theorizing and exploration play a critical role. Two literature reviews were sampled, focusing on different modalities of process improvement [P03] and agile BPM [P64], and thus not on the broader scope of our SLR. Design Science Research was present in eight papers, covering a measurement scale to guide managers' daily process management activities [P20], to offer a maturity model for organizational ambidexterity [P47, P69], to explain an ambidextrous analysis of business processes [P31], the "triple-diamond model" [P62, P67, P68], and the "Business Process Design Space [P70]. 


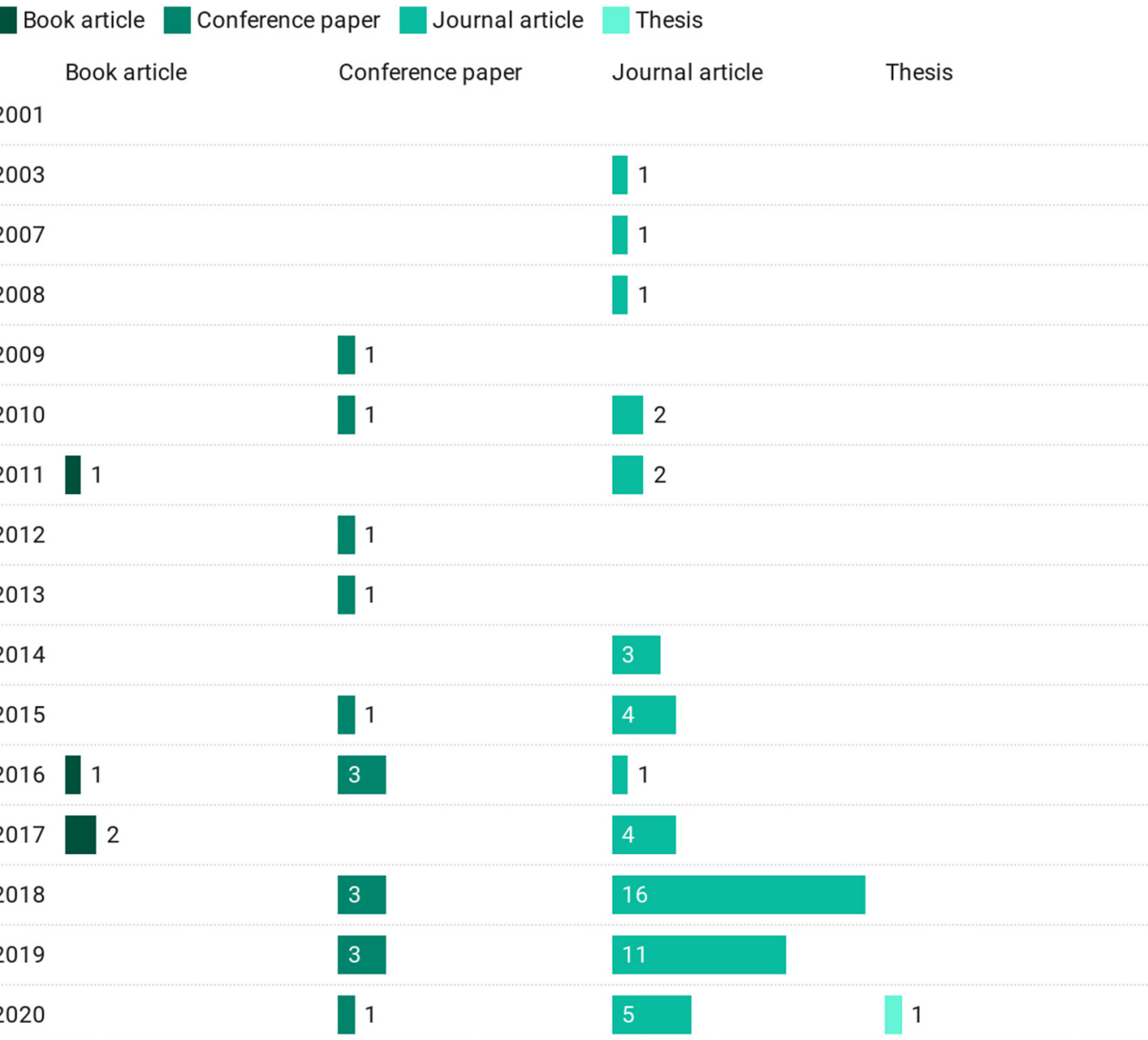

Figure 2. Publication types over time $\mathrm{N}=71$.

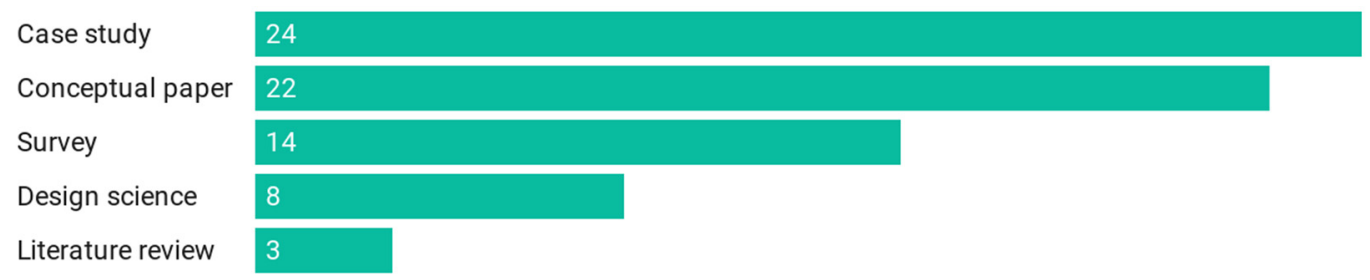

Figure 3. Research methods in the literature sample. $\mathrm{N}=71$.

\subsubsection{Research Centers-Geographic Distribution}

Based on the country of origin of the first author, Figure 4 shows that most of the research stems from the US, a few Western European countries (i.e., mostly Germany and Italy), and to a lesser extent from China and Australia. A few research centers seem to be predominant (particularly the University of Liechtenstein with four papers, University of Bayreuth with three papers and Fudan University with three papers), reflecting their strong interest in BPM and digital innovation, whereas at the same time the topic is not yet noticed in other countries across the globe (i.e., in particular in Europe, South America and Asia). Hence, this observation issues a strong call to researchers to investigate ambidextrous BPM in other research centers and cultural settings as well, in order to fully grab the effect of different business contexts and cultures. 


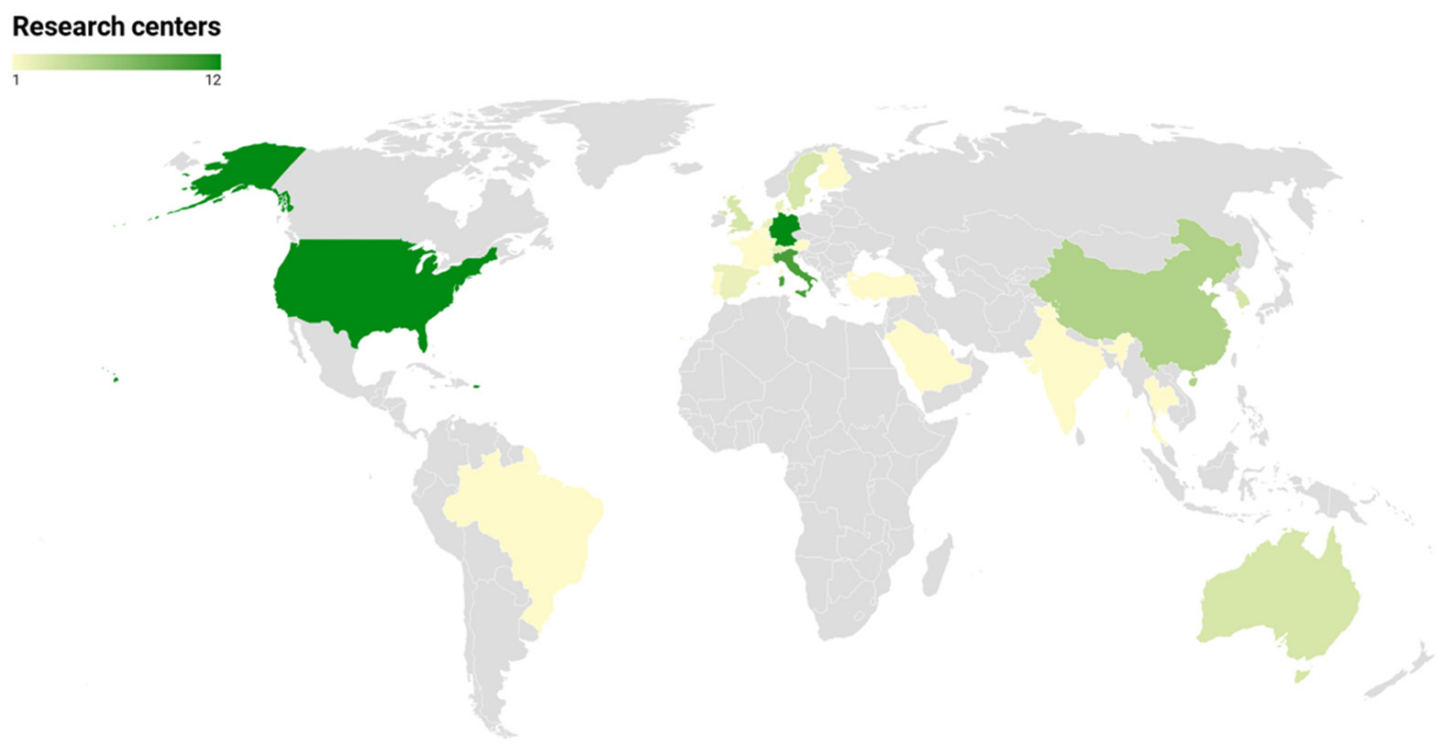

Figure 4. Geographic distribution of research centers. $\mathrm{N}=71$.

\subsection{Findings for SLR-Q2 (Conceptualization)}

Since BPM ambidexterity is a relatively new concept in Information System research, we did not observe a widely accepted definition of this term in our sample. Nevertheless, we uncovered two main research streams, which conceptualize ambidexterity in a distinctive manner:

- The first research streams views ambidexterity as the balance between explorative and exploitative processes. This stream focuses on ambidexterity defined as the balancing act of opposing activities of exploration and exploitation [P40]. In the context of BPM ambidexterity, it primarily means researching explorative BPM, and identifying strategies to resolve the tension between exploration and exploitation, through structural or contextual strategies. In this context, BPM ambidexterity is defined as a managed balance equilibrium between exploratory and exploitative processes [P08].

- On the other hand, we identified papers that look at ambidexterity as an organizational capability, supported by BPM. This second research stream is based on conceptualizing both ambidexterity and BPM, as an organizational capability (see Section 2.2). In this context, BPM ambidexterity is defined as a dynamic capability, manifested through routines and practices, leading to and supported by process exploitation and exploration [P20]. The papers in this stream focus on providing strategies to grow this capability through various organizational enablers, as well as the broader concept of business-IT alignment.

Table 2 summarizes the mapping of ambidexterity in the sample to the two research streams.

Table 2. Overview of papers associated with the capability and balance streams. $\mathrm{N}=71$.

\begin{tabular}{lll}
\hline \multirow{3}{*}{ Ambidexterity as a balance } & Structural ambidexterity & P01, P06, P11, P14, P17, P19, P20, P21, P30, P37, P38, P41, P42, P71 \\
\cline { 2 - 3 } & \multirow{2}{*}{ Contextual ambidexterity } & $\begin{array}{l}\text { P03, P05, P07, P18, P24, P25, P27, P28, P31, P33, P35, P37, P38, P42, } \\
\text { P58, P62, P65, P66, P67, P68, P70, P71 }\end{array}$ \\
\hline \multirow{3}{*}{ Ambidexterity as a capability } & Capability growth & $\begin{array}{l}\text { P02, P09, P13, P15, P32, P34, P39, P44, P45, P46, P47, P48, P49, P50, } \\
\text { P51, P52, P53, P54, P55, P56, P57, P61, P69 }\end{array}$ \\
\cline { 2 - 3 } & Business-IT alignment & P04, P12, P16, P22, P23, P36, P40, P61 \\
\hline
\end{tabular}


The distribution of sampled papers between the two streams is displayed in Figure 5, visualizing that both research streams were almost equally represented, with the research stream focusing on the balancing act being slightly more present in current literature.

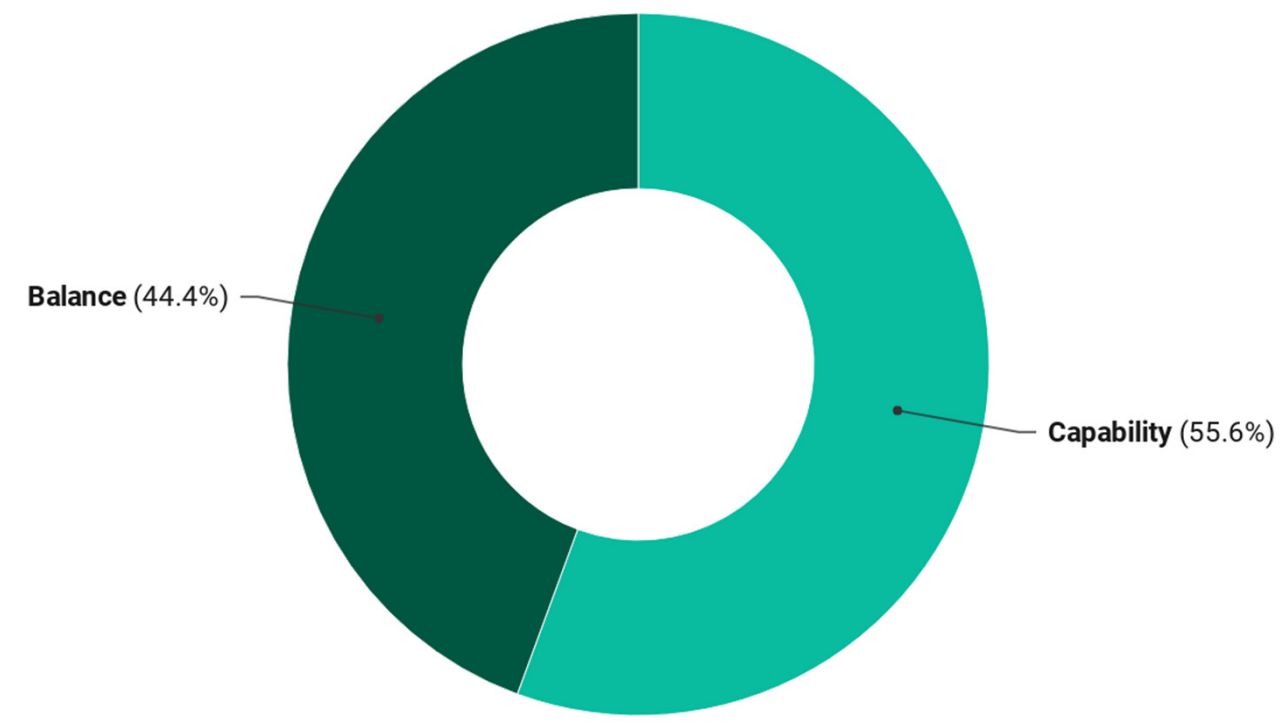

Figure 5. Distribution of the research streams in the literature sample $(\mathrm{N}=71)$.

We further defined the two research streams through various antecedents and related concepts, as visualized in Table 3. The balancing act of ambidexterity seems closely related to developing strategies to resolve this contradictory tension (e.g., contextual or structural approaches), as well the more holistic theme of paradox thinking in management [P45]. From the BPM lifecycle standpoint, the most relevant capabilities to resolve the tension were the process design and optimization phases [P11, P14, P44].

Table 3. Theories associated with the research streams.

Ambidexterity as a balance between explorative and exploitative process
- $\quad$ Contextual and structural ambidexterity [P01, P20]

- $\quad$ Paradox thinking [P45]

- $\quad$ Process design and process optimization [P11, P14, P44]

- $\quad$ Exploratory BPM [P45, P62, P67, P68]

Ambidexterity as a capability, supported by BPM

- $\quad$ Enterprise architecture [P58]

- $\quad$ Resources based view [P02]

- Dynamic capabilities [P02, P10, P49]

- $\quad$ Processes, structures, cultures [P50]

- $\quad$ Organizational learning [P19, P42]

- $\quad$ Social capital [P55]

- $\quad$ Business Process IT Ambidexterity [P16, P22, P40]

Figure 6 presents the evolution of the two research streams over time. It shows that the capability stream received particular interest in academia during the years 2019-2020, whereas the balance stream has been benefiting from a continuous increase in academic interest over the years. This may be attributed to the growing interest in papers focusing on exploratory BPM. 


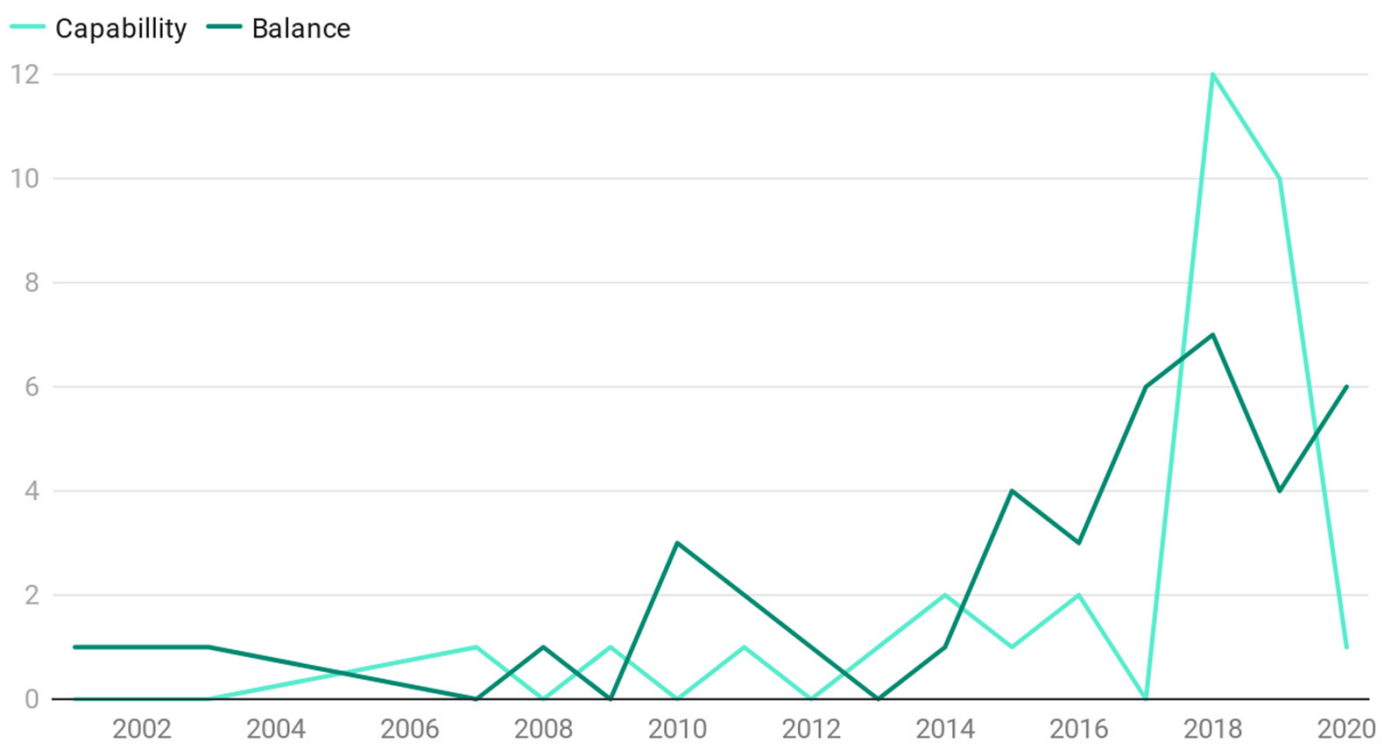

Figure 6. Distribution of the two research streams over time. $\mathrm{N}=71$.

On the other hand, the capability view of ambidexterity, rooted in enterprise architecture, positions both BPM and organizational ambidexterity as capabilities which need to be developed in order for organizations to succeed. This can be framed in the context of the resource-based view [P02] and dynamic capability view [P10] of an organization. In this context, researchers focused on growing organizations' capabilities, rather than resolving tensions. This increase in capabilities of an organization can be achieved through organizational learning [P42], the growth of social capital [P55], or the maturity of organizations' processes, structures and cultures [P50]. In the context of BPM, the focus was on the broader Business Process Orientation defined through the organization's culture and structures [27].

Subsequently, we provide more details about both research streams.

\subsubsection{Ambidexterity as a Balance between Explorative and Exploitative Processes}

When analyzing the balancing act of exploration and exploitation, most researchers identified two strategies aiming at resolving the tension.

1. Structural ambidexterity for providing temporal (sequential) or spatial (structural) separation between exploitation and exploration;

2. Contextual ambidexterity for managing exploration and exploitation in one entity and timeframe.

As shown in Figure 7, the most common strategy for resolving organizational ambidexterity from the perspective of BPM was contextual. This reflects the fairly straightforward nature of structural solutions (i.e., exploratory processes were separated in distinct structural entities from the exploitative ones), as well as the growing body of evidence about the limitations of such setups due to cultural tensions, the lack of communications and resource sharing between the separated entities [P13, P18].

\section{Contextual $57.1 \%$}

Structural $\quad 42.9 \%$

Figure 7. Distribution of the two types of ambidexterity in the literature sample ("balance stream"). $\mathrm{N}=31$. 
Contextual ambidexterity, on the other hand, provided an interesting challenge for $\mathrm{BPM}$, as it put the responsibilities on individual managers and employees to balance exploration and exploitation in their daily work routines. This ambidexterity type was translated into BPM as the provision of the necessary tools and practices for the employees for the modelling, optimization and management phases of the process lifecycle [P31, P45, P53].

Both ambidexterity types contributed to a growing understanding of the complimentary and self-reinforcing nature of the ambidextrous tension, which was encapsulated in the concept of paradox thinking [P45, P53]. Figure 8 visualizes the distribution of the strategies in the literature sample over time, showing a growing dominance of contextual ambidexterity in the recent years. This reflects the increasing interest in contextual strategies, focused on paradoxical reinforcement of the tensions [P13, P20].

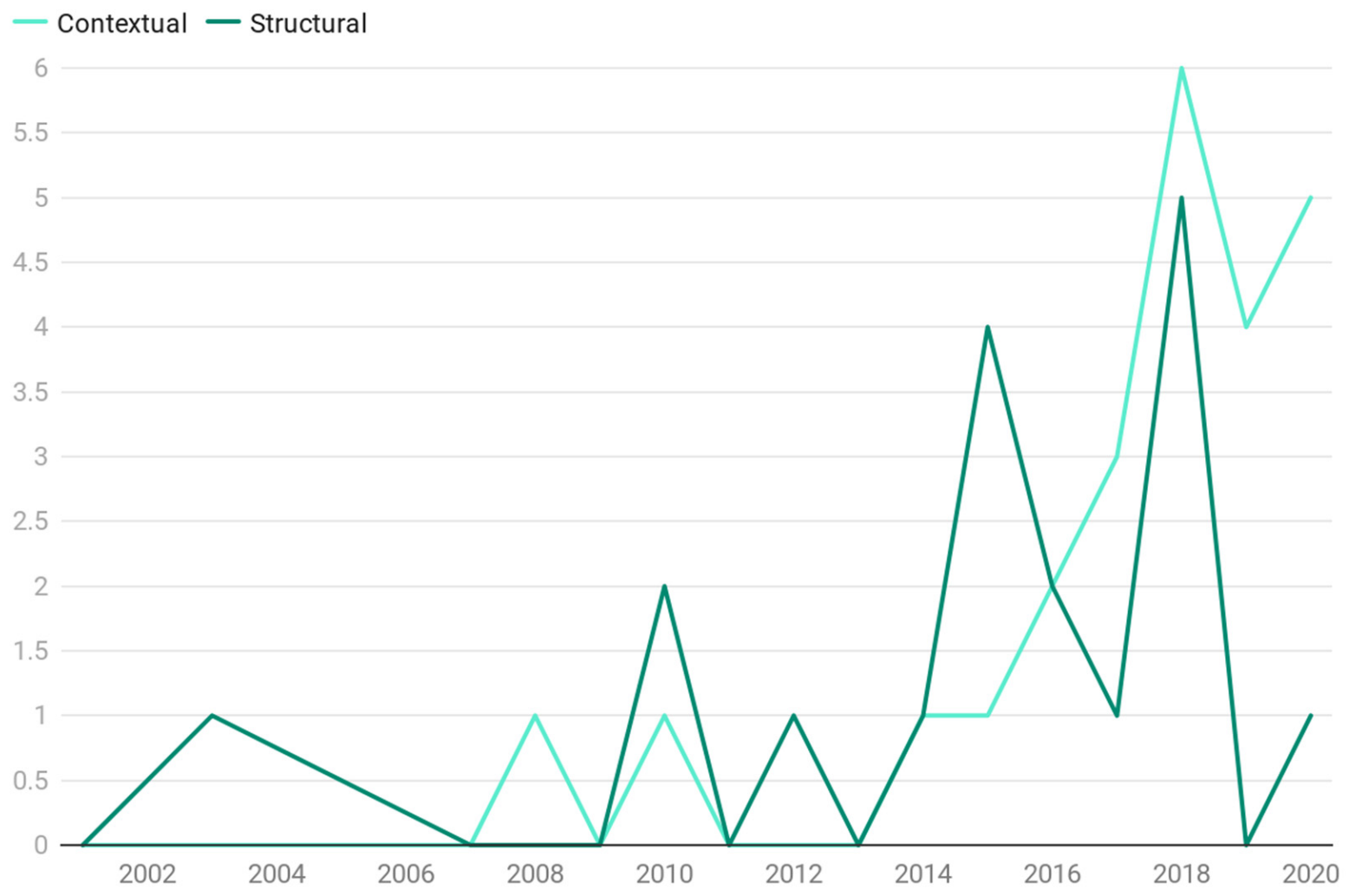

Figure 8. Evolution of the distribution of ambidexterity types in literature sample ("balance stream"). $\mathrm{N}=42$.

\subsubsection{Ambidexterity as a Capability, Supported by BPM}

Regarding the second research stream (i.e., organizational ambidexterity as a capability supported by BPM), we inquired how BPM could actually support ambidexterity. In the SLR sample, we found two perspectives to answer this question: (1) capability growth, and (2) business-IT alignment (see Table 2).

Firstly, capability growth refers to the increase of the overall organizational capabilities. For instance, three studies [P09, P15, P51] argued and provided evidence that TQM principles and practices deliver contextual OA (but interestingly not the structural type). [P13] argued that process optimization could actually lead to exploratory activities through the increase of the organization's resource and knowledge capacity, as well as its managerial vision. Similarly, [P50] conceptualized processes, structures and cultures as "the three-legged stool" (p. 1)—a balanced, self-reinforcing mix which facilitated OA. There were several other more specific enablers of OA identified by the researchers, such as: business process customization due to enterprise mobile systems [P34], big data analytics-capable business process management systems [P46] or underlying variables in BPM (knowledge 
transfer, knowledge conversion, ambiguity and feedback to change) [P52]. Alternatively, BPM could increase OA through cultural change [P15], the support of change management [P52] or strategy implementation [P54]. BPM capabilities could also act as a moderator of OA [P36, P48]. Finally, [P47] and [P70] identified business processes as part of the "routines" component of their model OA maturity. This relationship could also be inverse: the growth of the ambidextrous organizational capability may drive the maturity of BPM processes [P02].

Secondly, the focus was also on business-IT alignment which was enabled by BPM, and in turn leads to greater organizational ambidexterity. This can be conceptualized as: the synergy between business processes and IT [P04], the IT usage [P12], Business Process IT capabilities [P16, 23, 41] or the enabling role of IT [P23, P66].

In conclusion, we can state that there is already ample evidence in the literature that BPM ambidexterity can be conceptualized in a dual way: as a state of balance equilibrium between exploitative and explorative processes, and as a dynamic capability delivering process exploration and exploitation. As such, this overview helps orient scholars to the different dimensions that are present so far.

\subsection{Findings for SLR-Q3 (BPM Ambidexterity Aspects)}

In the next research question, we tried to deconstruct BPM ambidexterity by looking at it through the different BPM capability areas, mentioned in Section 2.

As presented in Figure 9, the BPM capabilities which were mostly associated with OA are process management, process optimization and process modelling. This reflects the fact that radical process innovation can be primarily expected in the process modelling and process optimization phases of the process lifecycle [P20, P44], and then in the broader context of process management [P06, P29, P46]. Interestingly, we observed that the BP modelling phase seems most strongly associated with the balance stream, which reflects the explicit need for modelling exploratory processes in the balance approach [P31, P45, P60].

\begin{tabular}{llll} 
& Balance & Capability \\
\cline { 2 - 3 } BP modelling & 13 & 1 \\
BP deployment & 0 & 2 \\
BP optimisation & 11 & 7 \\
BP management & 21 & 20 \\
BPO culture & 0 & 4 \\
BPO structure & 3 & 2
\end{tabular}

Figure 9. Distribution of BPM capability areas in the literature sample, divided by research streams. $\mathrm{N}=71$.

The BPO structure and culture capabilities were represented less than the stream of structural ambidexterity in our SLR sample. This can be explained by the fact that even when structural strategies for ambidextrous tensions were employed, the BPO capabilities were not explicitly present, and the papers were often associated with the Business Process Management stream [P19, P20].

Subsequently, we provide an overview of the main findings in BPM ambidexterity grouped by the BPM capabilities. Table 4 presents an overview of the main themes associated with each BPM capability. 
Table 4. Ambidexterity themes and BPM capabilities, based on [10].

\begin{tabular}{|c|c|c|c|}
\hline BPM Capability & Exploitation & Exploration & Paper IDs \\
\hline Process modelling & $\begin{array}{l}\text { Focus on execution, pain points. } \\
\text { Inside-out design }\end{array}$ & $\begin{array}{l}\text { Focus on change, opportunity } \\
\text { points, outside-in approach }\end{array}$ & $\begin{array}{l}\text { P02, P08, P17, P18, P24, P26, P27, } \\
\text { P28, P31, P60, P63, P66, P67, P68 }\end{array}$ \\
\hline Process deployment & $\mathrm{N} / \mathrm{A}$ & $\mathrm{N} / \mathrm{A}$ & P40, P76 \\
\hline Process optimization & $\begin{array}{c}\text { Process control, incremental process } \\
\text { improvement, decreasing the } \\
\text { variation }\end{array}$ & $\begin{array}{l}\text { Radical process improvement, } \\
\text { increasing the variation }\end{array}$ & $\begin{array}{c}\text { P03, P13, P16, P17, P19, P20, P21, } \\
\text { P16, P27, P30, P32, P34, P37, P45, } \\
\text { P50, P55, P70, P71 }\end{array}$ \\
\hline Process management & $\begin{array}{l}\text { Process alignment, efficiency, } \\
\text { compliance, rigor, standardization, } \\
\text { formalization, proceduralization, } \\
\text { operational excellence. }\end{array}$ & $\begin{array}{l}\text { Process adaptability, flexibility, } \\
\text { experimentation, agility, deviance } \\
\text { and customer-centricity }\end{array}$ & $\begin{array}{l}\text { P06, P07, P10, P11, P12, P16, P17, } \\
\text { P20, P22, P23, P25, P26, P27, P28, } \\
\text { P29, P33, P35, P36, P37, P38, P40, } \\
\text { P41, P43, P44, P45, P46, P47, P48, } \\
\text { P49, P50, P51, P53, P54, P56, P59, } \\
\text { P61, P62, P64, P65, P66, P69 }\end{array}$ \\
\hline Process-oriented culture & $\begin{array}{l}\text { Control, accuracy, discipline, } \\
\text { security, improvement, refinement, } \\
\text { deeper and more technical } \\
\text { awareness of implemented systems } \\
\text { and business process specifics }\end{array}$ & $\begin{array}{l}\text { Creativity, flexibility, } \\
\text { experimentation, risk taking, broad } \\
\text { understanding of the business and } \\
\text { market, also an overview of modern } \\
\text { technological innovations }\end{array}$ & P09, P15, P39, P57 \\
\hline Process-oriented structure & $\begin{array}{l}\text { "Supply side" structure (regular } \\
\text { maintenance and upgrades and } \\
\text { relatively simple new acquisition); } \\
\text { functional structure }\end{array}$ & $\begin{array}{l}\text { "Demand side" structure (complex, } \\
\text { strategic, innovation oriented and } \\
\text { large scale change related), } \\
\text { cross-functional structure }\end{array}$ & P01, P04, P05, P14, P57 \\
\hline
\end{tabular}

\subsubsection{Process Modelling (=14 Papers)}

Process modelling is the phase where the actual design of disruptive and radically innovative processes takes place [P31]. [P14] argued that process modelling should be driven by opportunity points (i.e., not pain points as is the case of traditional exploitative processes) and be based on an opportunity-driven, "outside-in" approach. [P66] argued that too much focus on the "as-is" process modeling hinders disruptive innovation.

According to several researchers [P08, P24, P25, P31, P42, P54], an integration of design thinking techniques into process modelling phase will enable explorative BPM. Additionally, process mining played a critical role in process discovery, also in the context of digital innovation. Nevertheless, [P66] argued that the emphasis should be rather on identifying patterns and opportunities for 'positive deviance' (i.e., deviating from norms, but positive in effect or intention). [P18] asserted that entrepreneurs who enact radical innovation also design a portfolio of processes using so-called 'bricolage' (Levi Strauss, 1966), where the user has to negotiate, improvise and compromise to make the change occur.

Finally, some researchers [P67. P68] proposed a model for process design based on the principles of divergent and convergent thinking (i.e., "Triple Diamond Model") to foster explorative BPM.

\subsubsection{Process Deployment ( $=2$ Papers)}

As expected from our research gaps, little research was observed in the field of deploying ambidextrous business processes. Regarding process monitoring and control, [P40] confirmed that BPM could support both exploitative and exploratory processes. According to [P76], process execution needed to be more flexible and adaptive, for instance in adaptive case management systems (i.e., those which could be adapted by users at run time).

\subsubsection{Process Optimization (=18 Papers)}

The process optimization phase was arguably the most important one in the process lifecycle from the point of view of radical innovation [P21], where radical process improvement could take place [P20]. For this reason, several researchers developed frameworks addressing this phase. In particular, [P19] reflected on the critical component of process optimization that had to be the variation decreasing and variation increasing activities. 
Next, [P30] proposed a new methodology of process evaluation (called PCM), which aimed to support exploration, and provide a platform for involving stakeholders in the process optimization phase. [P03] provided a framework for deciding on the most appropriate, context aware optimization method (covering Six Sigma, benchmarking, reengineering and process mapping). [P71] provided an in-depth conceptual model on how processes needed to be adapted in the process optimization phase to be exploratory, as a set of 7 "design patterns". Finally, [P70] focused on a 'Business Process Design Space', guiding practitioners on 19 dimensions which needed to be considered.

From the capability research stream, [P27] and [38] studied the opportunities provided by big data capabilities for process optimization, and [P47, P69] proposed a maturity model for organizational ambidexterity, seeing BPM as an enabler of one of the capability areas ('routines').

\subsubsection{Process Management (=41 Papers)}

The process management capability was visible both in the capability, and balance research streams (Figure 9). In relation to the balance view of BPM ambidexterity, the researchers focused on defining exploratory business processes, which were expected to be adaptable [P03, P66], agile [P06, P64], flexible [P10, P12], ad-hoc [P15] and customer centric. Furthermore, researcher provided prescriptive guidance for ambidextrous process management, for instance [P34] argued that big pharma enterprises following structural ambidexterity should focus on business process standardization to manage big data, whereas enterprises following contextual ambidexterity should rather focus on output standardization in a big data context. This can be explained by the need to mitigate the downsides of structural ambidexterity (e.g., inter-organizational conflict or misalignment of processes within an organization). Finally, [P66] and [P17] stressed the need of interweaving business and private processes in the context of digital innovation (i.e., the inter-organizational BPM ambidexterity).

On the other hand, process management was also strongly linked with practices associated with building organizational capabilities supporting ambidexterity. For instance, [P53] proposed to apply three ambidextrous practices: (1) "novelty via memory" (i.e., finding a balance between existing and new knowledge), (2) "agility via focus" (i.e., finding a balance between focus and flexibility), and (3) the potential for improvisation (i.e., tackling extraordinary situations with an element of unexpectedness, as well as correcting trivial deviations). In the context of the dynamic capabilities, [P31] claimed that innovation in production and IT processes led to greater organizational ambidexterity, while this was not the case for logistics processes. The researchers explained this by the fact that the logistics processes were less focused on exploration and radical innovation.

\subsubsection{Process-Oriented Culture ( $=4$ Papers)}

There were relatively few papers discussing process-oriented culture. The primary studies on cultural aspects of BPM ambidexterity [P09, P15] highlighted the need for a culture that supported creativity, flexibility, search, experimentation, and risk taking. This author also claimed that BPM actually better explained an exploitation culture (i.e., for security, discipline, control, improvement), which was refuted by other authors insisting on the self-reinforcing nature of exploitative and explorative activities [P13, P20]. [P57] in a case study on NASA, claimed that public-service culture might not be supportive of ambidexterity, due to excessive administrative procedures, and resulting inertia and conservatism. Nevertheless, there was a substantial research gap on the cultural context of BPM ambidexterity.

\subsubsection{Process-Oriented Structure (=5 Papers)}

So far, the structural aspects remained relatively unexplored in literature, and the main contribution of literature on the structural aspects of BPM ambidexterity was the recommendation on providing dual structures for exploration and exploitation [P02, P04, P14, P57]. 
[P05] built on this, recommending cross-functional structures for disruptive (break-through) innovation processes, and functional structures for incremental innovation processes.

\subsection{Findings for SLR-Q4 (Practical Guidelines)}

In order to structure the guidelines for the practitioner, we grouped them into three sub-questions, as mentioned in Section 3.

\subsubsection{Adapting Existing BPM Practices towards Explorative Ones}

First, we discuss the sub-question about how existing BPM practices can become more explorative. The recommendations found in literature were grouped into six clusters, as listed in Table 5.

Table 5. Main recommendations for implementing exploratory processes.

\begin{tabular}{cc}
\hline Recommendation & Paper IDs \\
\hline Enrich with “Design Thinking” techniques (e.g., the Ambidextrous Analysis of Business & P08, P24, P25, P31, P42, P54 \\
Process method) & P24, P46, P60, P64 \\
Add agile and lean concepts to processes & P45, P62, P67, P68, \\
Apply divergent-convergent thinking (e.g., "triple diamond model”) & P18, P53 \\
Adopt the “bricolage concepts" [38], or "improvisation” & P20, P21, P30, P50, P70 \\
Follow new prescriptive models (e.g., questionnaires), advocating specific activities & P51, P52 \\
Adopt selected practices from existing methodologies (BPR, TQM) & \\
\hline
\end{tabular}

In general, the various techniques aimed to: (1) exploit internal capabilities, and (2) explore external technological and business opportunities, which were at the outset not known to the process owners. This approach is visualized in Figure 10.

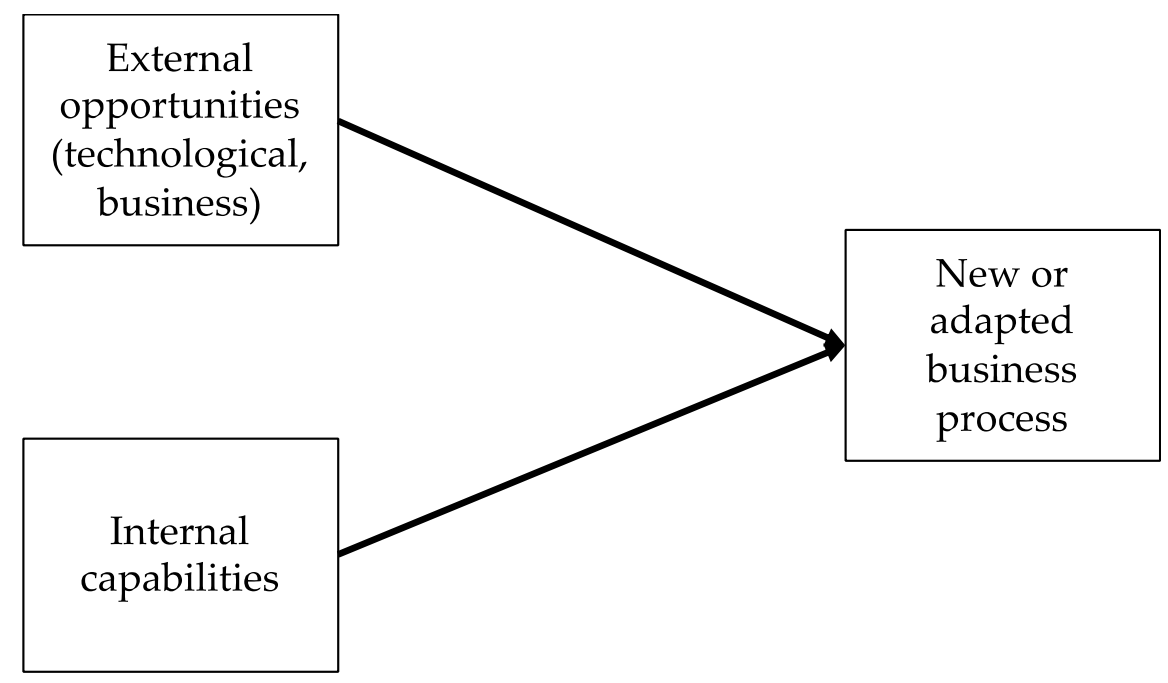

Figure 10. Conceptualization of the approaches for exploratory BPM, based on the review of literature sample.

In practice, the recommendations observed in our sample addressed various dimensions of the approach, visualized in Figure 10. More specifically, they either focused on:

(1) the actual ideation, either structured around the Design Thinking techniques [P24, P25, P31, P54] or explicitly unstructured in the context of 'bricolage' or 'improvisation' $[P 18$, P53]. Alternatively, the ideation could also be supported through the "Business Process Design Space" [P67, P70];

(2) the results of the ideation which should follow rapid iterations and customer-focused experimentations, based on Agile principles [P24]; and finally 
(3) activities delivering integration ('convergence') of the business opportunities into the organizational context [P62, P67, P68].

Looking more closely at the recommended frameworks, Design Thinking seemed to provide an opportunity for broadening the scope of BPM [P31]. Design Thinking is a set of principles including empathy, prototyping and acceptance of failure, facilitating product and service innovation around customer-centricity [P24], and which may help organizations "learn how to learn" [P42]. For instance, [P31] designed a new method for business process modelling called the "Ambidextrous Analysis of Business Process" (A2BP) for structuring the process modelling phase in line with the Design Thinking approach, namely by following the: (1) empathy, (2) define, (3) ideate, and (4) prototype steps. For each of the steps, several exploration techniques were proposed, such as empathy maps, personas, or user journeys. The A2BP method provided an excellent platform for implementing rapid innovation, but it fell short of delivering a technique for integrating innovation into the organizational context, and as such provided a limited, structural solution to BPM ambidexterity. On the other hand, [P08] proposed a method called Tangible Business Process Modeling (TBPM), providing tangible, physical prototypes to be used in the process modelling phase.

Furthermore, [P67, P70] claimed that, despite various process redesign techniques, the actual design of radically new processes in BPM was still lacking. For that reason, the researchers presented a "Business Process Design Space", aiming to allow practitioners to "explore, question and rethink" business processes in the process optimization phase, consisting of six layers: (1) customer, (2) product/service, (3) business process, (4) organization, (5) information and (6) technology.

Beyond the ideation phase, [P24, P46] and [P66] proposed to enrich BPM with agile methods in order to build greater alignment with changing requirements through fast feedback and short design cycles. An integration of concepts from A/B testing in the context of DevOps seemed to provide opportunities in the process optimization phase. In the process deployment phase, robotic process automation was expected to become more important. An example of an agile process redesign technique was the "NESTT approach" for rapid process redesign in less than 20 days [P65], focusing on starting by describing the ambition for the future process. Additionally, [P46] talked about building adaptable and easily iterated BPM systems. Alternatively, [P24] provided a counterfactual recommendation for driving disruption through BPM by enumerating tactics not to follow: (1) 'Too slippery to be caught' (i.e., sticking to your long-term improvement plan), (2) 'Too heavy to be moved' (cast your processes in concrete), and (3) 'Too cushioned to be hurt' (slow down by shock absorbers). This view reinforced the need to increase agility in BPM.

Furthermore, improvisation was a recurring theme in the literature, sometimes referred to as "bricolage" [P18], which was defined as tinkering and recombining objects in a given process in an entrepreneurial context in order to give them new purpose. [P18] advocated the use of "bricolage" in the process modelling phase when the entrepreneur does not have an established vision of the business opportunity, and had to develop the process, with "anything that was at hand" in an unplanned manner, where outcomes were unclear. This was closely linked to the theme of "improvisation" which was defined as "accommodating available resources in the absence of a plan" [P53, p. 7]. Another recurrent theme was the inclusion of open innovation techniques, as argued by [P54] and [P59].

Most recently, [P62, P67, P68] proposed a "triple diamond model" as a blueprint for practitioners to integrate explorative, opportunity-driven processes in their BPM practice. The objective of this model was to create new processes, offering a new value proposition, through a set of divergent and convergent exploratory activities focusing on business and technology exploration. The name "triple diamond" refers to the three focuses of divergent and convergent thinking: (1) business, (2) technology and (3) integration. A teaching curriculum is expected to be published about this model in 2021. The model provided a holistic view on the integration of explorative processes, but did not deliver extensive guidance on how to ideate on innovation opportunities, and as such is complementary to the approaches 
based on Design Thinking. Moreover, [P71] argued that the convergent-divergent thinking approach was prone to biases. [P45] extended the convergence-divergence model to the whole organization, proposing a "paradox process model" resembling a "learning spiral" where organizations constantly moved between convergence (learning and refinement) and divergence (outside of the equilibrium).

The next category of methods focused on prescriptive methods for delivering exploration in BPM. [P30] proposed the Prioritization and Categorization Method (PCM) for the implementation of exploratory BPM, consisting of two models: a process assessment heatmap, and a process categorization map, which were used to support the decisionmaking process, in a context-aware, explorative way. In another approach, [P21] advised to incorporate customer perspective and customer orientation, as a strategic objective in the process modelling phase.

Finally, some researchers proposed to repurpose existing BPM methodologies. In particular, [P51] highlighted several practices in Quality Management practices which promoted process exploration, through the generation of new knowledge and client centricity, such as affinity diagrams, quality function deployment techniques, or collaborative sketching. It has to be nevertheless underlined that the core objectives of Quality Management remained exploitative activities: quality assurance, control and improvement. On the other hand, [P52] proposed integrating Business Process Reengineering practices with Total Quality Management, as a method for delivering BPM ambidexterity. This approach had the benefit of relying on two established frameworks, however the researchers admitted in their study that it created an issue of "ambiguity": communication and interpretation challenges when working with the two frameworks.

\subsubsection{Balancing Explorative and Exploitative BPM}

Secondly, we focused on providing guidelines to practitioners on how to balance explorative and exploitative BPM in an organization. This question was at the core of BPM ambidexterity, given the definitions in Section 4.2.

In line with the OA literature (Section 2.1), the strategies to resolve the tension could be:

- Structural: with a focus on separating structurally the explorative processes, from the exploitative ones. This provided an isolated environment to run explorative processes, such as for example the A2BP method [P31]. Most researchers nevertheless agreed, that structural approaches faced several limitations (siloes, lower integration of innovation, cultural barriers etc.) [P20];

- Contextual: with a focus on integrating explorative and exploitative processes, as for example in the "Triple Diamond Model" [P62, P67, P68].

In the Table 6, we summarize some of the technique available in the sample, mapped to structural or contextual strategies:

Table 6. Examples of BPM methodologies and practices which can be associated with contextual or structural ambidexterity.

\begin{tabular}{cc}
\hline Structural exploratory techniques & $\begin{array}{c}\text { Design Thinking techniques [P24, P25, P31, P54], } \\
\text { Bricolage/Improvisation [P18, P53], Agile approaches } \\
\text { [P24, P46, P60, P64] }\end{array}$ \\
\hline Contextual ambidexterity techniques & $\begin{array}{c}\text { "Triple diamond model" [P45, P62, P67, P68], } \\
\text { Prioritization and Categorization Method [P30] }\end{array}$ \\
\hline
\end{tabular}

Answering this question, researchers such as [P67, P68] emphasized the need to maintain context awareness, and depending on the context to deploy contextual or structural strategies. [P19] proposed that the balance between explorative and exploitative activities was established based on the following factors: product type, market volatility, market focus and rate of process innovation on the one hand, and the organization's chosen competitive strategy on the other. 
Several researchers attempted to formalize this decision point by delivering formal frameworks. For instance, [P03] proposed a practitioner framework called "Specify, Analyze, Monitor" (SAM) which helped practitioners decide which type of process improvement approach to adopt, which corresponded to the concepts of incremental (e.g., TQM, Six Sigma, process mapping) and radical (e.g., benchmarking, reengineering) process improvement. The SAM model was based on assessing the potential impacts and risks of each approach. Similarly, [P67] devised a context-aware BPM method assessment and selection method (CAMAS Method) for helping practitioners select the appropriate BPM method, based on a given context. The researchers collected a database of 103 BPM-related methods, and provided a decision model based on the five lifecycle stages of Rosemann \& vom Brocke (2015), the exploration or exploitation focus, and the contextual factors of vom Brocke, Zelt, \& Schmiedel (2016). It was confirmed that the BPM methods for exploration still remained limited, and deserved more research attention. Finally, [P40] provided the "Business Process IT Capability Framework" for helping practitioners decide whether to invest into explorative or exploitative capabilities.

In itself, the balance between exploration and exploitation could also be dynamic, and changing depending on the market forces. For instance, [P43] proposed a dynamic approach to balancing ambidextrous tensions through capability-building processes (to balance exploration and exploitation) and capability-shifting processes (to adapt this balance to the changing requirements), admitting the adaptation balance was not yet well researched.

In the context of the contextual ambidexterity, the development of ambidextrous capabilities is of critical importance, which brings us to the next sub-question.

\subsubsection{Organizational Capabilities to Facilitate BPM Ambidexterity}

The final practical sub-question related to the required organizational changes (i.e., structure, culture) to facilitate BPM ambidexterity, which is linked to the capability stream of research in BPM ambidexterity.

In our research sample, we identified the following two themes:

- Culture and leadership: at the core BPM ambidexterity is instilling a culture of creativity, flexibility, experimentation and risk taking [P13, P15]. Our sample revealed five guidelines on how to achieve this: (1) involvement and a joint understanding (common language) of employees in order to support enablement [P39], (2) management focusing on facilitating communications and openness in knowledge management to grow the organization's social capital [P55], (3) creating a learning culture and "learning to learn" [P42], (4) adopting an "ambivalent leadership style" integrating and alternating the contractual setting with the visionary and "unconventional" ones [P44], and (5) relying less on performance metrics, which according to [P8\} support incremental innovation, rather than radical one. Interestingly [P11] claimed that Western cultures might have greater difficulty adopting contextual ambidexterity than Eastern cultures, as the Western approach is built on "polarized either-or thinking", and a lower tolerance of contradictions and paradoxes.

- Role of technology: [P10, P12] and [P32] hypothesized that various IT-related and BPM-related managerial capabilities, as well as their learning behavior will support the growth of BPM ambidexterity in an organization. The role of IT as an enabler of BPM ambidexterity (i.e., in the context of team processes) was reinforced in [P23] through the simultaneous support of process standardization and process agility. [P27] and [P37] also added the big data dimension, as an enabler of BPM ambidexterity, through the use of data to improve internal process, as well as increase client orientation and adaptation to market changes. Similarly, [P34] highlighted the role of mobile technology, in support of BPM ambidexterity. On the other hand, digital transformation (i.e., in particular assets digitalization, digitally based process integration; and disruptive decision-making through analytics) may resolve the exploration-exploitation tension in the context of BPM [P38], by nurturing innovative, exploratory thinking. 
In our literature sample, we also identified a relevant discussion on whether instilling BPM culture supports ambidexterity. [P15] argued that adopting BPM might instill a culture of exploitation, and management needed to plan activities to counteract the exploitation bias. Similarly, [P29] provided an analytical model arguing that BPM was less recommended for organizations pursuing radical innovation. On the other hand, this was in contradiction with other researchers, with [P20] stressing that incremental process improvements reinforced radical process innovation, which was in line with the view of paradox thinking, and exploitation reinforcing exploration, through organizational capability growth [P13].

Finally, [P41] stressed that there was no one-size-fits-all approach, and the approach had to be customized depending on the context (competitive environment).

\section{Discussion}

The SLR analysis has provided essential insights into the topic of BPM ambidexterity. We first discuss the BPM ambidexterity findings, before highlighting the limitations of the study and proposing a related research agenda with concrete calls and future avenues.

\subsection{On the Importance of BPM Ambidexterity}

Although innovation has been closely linked to BPM since the origins of this discipline [P67], various methods such as "redesign", "reengineering", and "improvement" have been used interchangeably [P65]. Moreover, the BPM discipline seems to have become overtly focused on exploitation and optimization in the recent years, rather than disruptive innovation [P69]. Currently, digital innovation and transformation can actually "obliterate" whole processes, putting fundamentally into question the need to optimize them [P66].

In this context, and following the call for research on ambidextrous BPM by Rosemann [P13] in 2014, various researchers have started addressing this topic broadly within two streams: (1) in the context of BPM methods and techniques, inquiring how to grow explorative processes, and how to resolve the resulting tension between exploration and exploitation, and (2) within the broader organizational capability, where BPM capabilities support the organization to become ambidextrous.

\subsection{Managerial Guidelines}

The literature sample has provided us with a substantial set of guidelines on how to implement BPM ambidexterity in an organization, covering the development of exploratory BPM practices, strategies of balancing them with existing exploitative ones, as well as developing organizational capabilities which would enable this transformation.

Based on the analysis and consolidation of existing guidelines, we have proposed decision steps in Figure 11, which cover the necessary decision points in the implementation of BPM ambidexterity, starting with: (1) deciding whether to adopt exploratory practices based on contextual and strategic factors [P19], (2) choosing the appropriate balancing strategy for exploratory and exploitative activities [P03, P67], followed by (3) implementing the most appropriate BPM technique(s). These high-level decision points are intended for decision-makers, when considering or planning to implement BPM practices supporting higher levels of innovation and disruption, while maintaining the organization's focus on operational excellence. The steps also represent the three levels of managerial decision making, respectively strategic (i.e., decision to pursue radical innovation), tactical (i.e., organizational design for the strategy), and finally operational (i.e., appropriate BPM techniques).

The novel BPM techniques are based on either: (1) integration of other ideation and innovation frameworks such as Design Thinking, Agile, Lean or Open Innovation or the concept of convergent-divergent thinking, (2) re-implementation in an ambidextrous setting of existing techniques, such as Business Process Reengineering, or elements of Quality Management, or (3) prescriptive questionnaire and models based on best practices. The outward-looking, disruptive innovation is expected to take place in the modelling and optimizing steps in the process lifecycle, but it may fail without addressing the broader 
changes in organizations' capabilities, including the culture and structure. A consensus in the research exists that the culture and leadership style need to be built on openness, enablement of staff and promotion of experimentation and learning [P11, P15].

\begin{tabular}{|c|c|c|}
\hline $\begin{array}{l}\text { 1. Decide on the } \\
\text { exploration- } \\
\text { exploitation } \\
\text { balance. [P19] }\end{array}$ & $\begin{array}{l}\text { 2. Decide on } \\
\text { contextual or } \\
\text { structural } \\
\text { approach. [P03, } \\
\text { P67] }\end{array}$ & $\begin{array}{l}\text { 3. Implement } \\
\text { techniques } \\
\text { associated with } \\
\text { each approach. } \\
\text { (Table 6) }\end{array}$ \\
\hline
\end{tabular}

Figure 11. Decision steps in implementing BPM ambidexterity. (Source: own conceptualization based on the literature sample, and own analysis).

The concept of paradox and mutual reinforcement of contradictory processes has been pervasive in BPM ambidexterity [P45]. The paradox of exploration and exploitation as being self-reinforcing has been visible on the organizational level, through contextual ambidexterity, but also on the level of individual techniques, as for instance in the convergent-divergent thinking in the Triple-Diamond model.

\subsection{Research Agenda}

While OA has a longer tradition, the topic of BPM ambidexterity is still relatively new for which our study has uncovered some main research gaps:

- In our study, we proposed to outline decision steps for deciding on BPM ambidexterity implementation (Figure 11). Nevertheless, there are significant research gaps on: (1) the contingency factors for pursuing structural or contextual ambidexterity; and (2) guidance on integrating exploitative and exploratory BPM activities in a contextual setting. These two research avenues will be critical in providing practitioners with the appropriate toolset for implementing BPM ambidexterity in a given organization.

- Looking through the structural lens, there are only few frameworks for exploratory BPM, and there is little evidence for their effectiveness. Consequently, further elaboration on this topic will bring significant benefits for practitioners. A promising avenue for future research is the further integration of concepts from digital innovation with BPM [P66].

- Another major research gap relates to the cultural and structural settings of BPM ambidexterity. As argued by [27], the organizational context plays a critical role in successful BPM implementations. The findings in the literature are not only incomplete, but also to some extent contradictory: the researchers cannot agree if and how BPM can support an exploration culture [P13, P15]. Additionally, from practitioners' point of view guidance for instilling an appropriate BPM culture will be of significant value. Furthermore, the underlying mechanisms of the paradox perspective on OA [P45] will have to be further investigated to confirm if and how exploitative and explorative processes reinforce each other.

- In the context of digitization, the growth of digital platforms is seen as a critical enabler, and the topic of inter-organizational BPM ambidexterity [P17] will provide promising avenues for future research.

- Finally, the intersection of BPM ambidexterity and sustainability has not been previously explored in academia, and provides interesting avenues of research, within the trends of digital transformation and the green transition. Nonetheless, operational excellence is key.

\subsection{Limitations of the Study}

The main limitations of the study are two-fold, and are typical for SLR settings. First, due to the SLR protocol, we might have missed some papers, which would provide relevant context to this article, but which have not met the strict requirements of the search strategy 
in the SLR (i.e., in particular regarding the search terms and academic databases selected). To address this limitation, we deliberately targeted a combination of terms across multiple databases. The second limitations relates to timing. As the topic is still relatively new and dynamic, articles may have appeared after the cut-off date of the SLR. Nevertheless, despite those limitations, we believe that this overview paper will provide a valuable contribution to the future research on BPM ambidexterity.

\section{Conclusions}

In this paper, we have provided an in-depth study of the nascent topic of BPM ambidexterity through a Systematic Literature Review. Based on a literature sample of 71 papers, we have provided a dual conceptualization of the topic: as an organizational capability supported by BPM, and as a state of equilibrium balance between explorative and exploitative processes. We also used the capability framework of [27] to deconstruct the BPM capabilities from the standpoint of Organizational Ambidexterity. Our main practical contribution of the paper is the consolidation of hitherto research on BPM ambidexterity in the context of implementation guidelines for practitioners in three decision steps. Similarly, we identified several research gaps, addressing both the decision criteria for the exploitation-exploration tension, as well as the overall capability growth of the organization.

In sum, this paper is addressing the call by [13] for a systematic definition of domains, in which OA should be studied. Business processes provide a key dimension for the conceptualization and enablement of OA, and in turn OA delivers a conceptual model for the evolution of BPM. Answering to the question from the title of the paper: is BPM ready for ambidexterity? We have provided a consolidated conceptualization of this challenge, and the main avenues for future research, in order to let this domain advance further.

Author Contributions: Conceptualization, T.H. and A.V.L.; methodology, A.V.L. and T.H.; writingoriginal draft preparation, T.H.; writing-review and editing, A.V.L.; supervision, A.V.L. Both authors have read and agreed to the published version of the manuscript.

Funding: This research received no external funding.

Institutional Review Board Statement: Not applicable.

Informed Consent Statement: Not applicable.

Data Availability Statement: The underlying data for the Systematic Literature Review are available at the following location: https:/ / www.icloud.com/iclouddrive/02Wi8hVNTdhJP1_DxOegXKK1A\# Literature_sample.

Conflicts of Interest: The authors declare no conflict of interest.

\section{Appendix A Literature Sample $(\mathbf{N}=71)$}

\begin{tabular}{|c|c|}
\hline P01 & $\begin{array}{l}\text { Benner, M. J., and Tushman, M. L. (2003). Exploration, exploitation and process management: The productivity } \\
\text { dilemma revisited. Academy of Management Journal, 28(2), 238-256. https:/ / doi.org/10.2307/3094913 }\end{array}$ \\
\hline P02 & $\begin{array}{l}\text { Tarafdar, M., and Gordon, S. R. (2007). Understanding the influence of information systems competencies on process } \\
\text { innovation: A resource-based view. Journal of Strategic Information Systems, 16(4), 353-392. } \\
\text { https:/ / doi.org/10.1016/j.jsis.2007.09.001 }\end{array}$ \\
\hline P03 & $\begin{array}{l}\text { Siha, S. M., and Saad, G. H. (2008). Business process improvement: Empirical assessment and extensions. Business } \\
\text { Process Management Journal, 14(6), 778-802. https:/ / doi.org/10.1108/14637150810915973 }\end{array}$ \\
\hline P04 & $\begin{array}{l}\text { Ling, H., Zhao, F., and Wang, Y. (2009). Impact of Synergy Between IT and Business Process on Organizational } \\
\text { Performance: a Perspective of Ambidexterity Theory. In PACIS } 2009 \text { Proceedings (Vol. 116). Retrieved from } \\
\text { http:/ / aisel.aisnet.org/pacis2009/116 }\end{array}$ \\
\hline P05 & $\begin{array}{l}\text { de Visser, M., de Weerd-Nederhof, P., Faems, D., Song, M., Van Looy, B., and Visscher, K. (2010). Structural } \\
\text { ambidexterity in NPD processes: A firm-level assessment of the impact of differentiated structures on innovation } \\
\text { performance. Technovation, 30(5-6), 291-299. https:/ / doi.org/10.1016/j.technovation.2009.09.008 }\end{array}$ \\
\hline
\end{tabular}


Lee, G., DeLone, W. H., and Espinosa, J. A. (2010). The main and interaction effects of process rigor, process

P06 standardization, and process agility on system performance in distributed IS development: An ambidexterity perspective. In ICIS-International Conference on Information Systems (p. Paper 34). Retrieved from http:/ / aisel.aisnet.org/icis2010_submissions/34/

P07 Melnyk, S. A., Hanson, J. D., and Calantone, R. J. (2010). Hitting the target ... but missing the point: Resolving the paradox of strategic transition. Long Range Planning, 43(4), 555-574. https:/ / doi.org/10.1016/j.lrp.2009.11.004

P08 Luebbe, A., Weske, M. (2011). Bringing Design Thinking to Business Process. In: Plattner, H., Meinel, C., and Leifer, L. (2011). Design Thinking Understand-Improve-Apply. Retrieved from http:/ / www.springer.com/series/8802

P09 Moreno Luzon, M. D., and Valls Pasola, J. (2011). Ambidexterity and total quality management: towards a research agenda. Management Decision, 49(6), 927-947. https://doi.org/10.1108/00251741111143612

Xie, R., Ling, H., Zhang, C., Rong, X., Hong, L., and Cheng, Z. (2011). Effect of business process management on firm

P10 performance: An ambidexterity perspective. Business Management and Electronic Information (BMEI), 2011 International Conference On, 3, 341-345. https:/ / doi.org/10.1109/ICBMEI.2011.5920464

Backstrom, T. (2012). Incremental and radical innovation from a complex system theory perspective. In ISMOT 2012:

P11 proceedings of the 2012 IEEE International Symposium on Management of Technology: 8-9 November 2012, Hangzhou, Zheijiang, China.

Xie, R., Ling, H., Sun, Y., and Zhang, C. (2013). Towards the Ambidexterity of Service Processes: Im
P12 Managing of IT Usage and Organization Learning. In WHICEB 2013 Proceedings. 6. Retrieved from http://aisel.aisnet.org/whiceb2013/6/

P13 Berente, N., and Lee, J. (2014). How process improvement efforts can drive organisational innovativeness. Technology Analysis and Strategic Management, 26(4), 417-433. https:/ / doi.org/10.1080/09537325.2013.851376

Kohlborn, T., Mueller, O., Poeppelbuss, J., and Roeglinger, M. (2014). Interview with Michael Rosemann on

P14 ambidextrous business process management. Business Process Management Journal, 20(4), $634-638$. https:/ / doi.org/10.1108/BPMJ-02-2014-0010

Moreno Luzon, M. D., Gil Marques, M., and Arteaga, F. (2014). Driving organisational ambidexterity through process

P15 management. The key role of cultural change. Total Quality Management and Business Excellence, 25(9-10), 1026-1038. https:/ / doi.org/10.1080/14783363.2013.776768

Heckmann, C. (2015). The Impact of Business Process IT
P16 Research- in-Progress Papers (pp. 0-12). Retrieved from http:/ / aisel.aisnet.org/ecis2015_riphttp://aisel.aisnet.org/ecis2015_rip/23

P17 Lavikka, R., Smeds, R., and Jaatinen, M. (2015). A process for building inter-organizational contextual ambidexterity. Business Process Management Journal, 21(5), 1140-1161. https:/ / doi.org/10.1108/BPMJ-12-2013-0153

Le Loarne, S., and Maalaoui, A. (2015). How high-tech entrepreneurs bricole
P18 management for their activities. Business Process Management Journal, 21(1). https: / / doi.org/10.1108/BPMJ-03-2014-0024ï

Matthews, R. L., Tan, K. H., and Marzec, P. E. (2015). Organisational ambidexterity within process improvement:
P19 exploratory study of four project-oriented firms. Journal of Manufacturing Technology Management, 26(4), 458-476. https: / / doi.org/10.1108/JMTM-12-2013-0184

Ng, S. C. H., Rungtusanatham, J. M., Zhao, X., and Lee, T. S. (2015). Examining process management via the lens of

P20 exploitation and exploration: Reconceptualization and scale development. International Journal of Production Economics, 163, 1-15. https:/ / doi.org/10.1016/j.ijpe.2015.01.021

P21 Afflerbach, P., and Frank, L. (2016). Customer Experience Versus Process Efficiency: Towards an Analytical Framework About Ambidextrous BPM. In 37th International Conference on Information Systems (ICIS) (Vol. 4801, pp. 1-21).

P22 Heckmann, C., Hsu, J. S.-C., and Mädche, A. (2016). IT ambidexterity-conceptualization at the business process level. 24th European Conference on Information Systems, ECIS 2016.

Kwak, C., Lee, J., and Lee, H. (2016). Effects of information technology on team innovation and inter-team coordination:

P23 An exploratory investigation of process ambidexterity. In Proceedings of the Annual Hawaii International Conference on System Sciences (Vol. 2016-March, pp. 5309-5318). https:/ / doi.org/10.1109/HICSS.2016.656

Rösel, A. (2016). Are we ready for disruptive innovation. In: Kuhrmann, M., Münch, J., Richardson, I., Rausch, A., and Zhang, H. (2016). Managing Software Process Evolution: Traditional, Agile and Beyond-How to Handle Process Change. Springer International Publishing AG Switzerland. Retrieved from https:/ /link.springer.com/content/pdf/10.1007\%2F978-3-319-31545-4.pdf 


\begin{tabular}{cl}
\hline P25 & $\begin{array}{l}\text { Van Den Bergh, J., Işik, Ö., Viaene, S., and Helsen, E. (2016). Re-Positioning Business Process Management-Exploring } \\
\text { Key Capabilities for Successful Business Transformation. BPTrends. Retrieved from www.bptrends.com }\end{array}$ \\
\hline P26 & $\begin{array}{l}\text { Bala, H., Massey, A. P., and Montoya, M. M. (2017). The Effects of Process Orientations on Collaboration Technology Use } \\
\text { and Outcomes in Product Development. Journal of Management Information Systems, 34(2), 520-559. } \\
\text { https://doi.org/10.1080/07421222.2017.1334494 }\end{array}$ \\
\hline P27 & $\begin{array}{l}\text { Dezi, L., Santoro, G., Gabteni, H., and Pellicelli, A. C. (2017). The role of big data in shaping ambidextrous business } \\
\text { process management. Business Process Management Journal. https://doi.org/10.1108/BPMJ-07-2017-0215 }\end{array}$ \\
\hline & $\begin{array}{l}\text { Fleischman, A.; Schmidt, W.; Stary, C. (2017). Overcoming the Innovator's Dilemma in Disruptive Process Innovation } \\
\text { P28 }\end{array}$ \\
$\begin{array}{l}\text { Through Subject Orientation. In: Kurosu, M. (2017). Human-Computer Interaction User Interface Design, Development and } \\
\text { Multimodality. Lecture Notes in Computer Science (including subseries Lecture Notes in Artificial Intelligence and Lecture Notes } \\
\text { in Bioinformatics) (Vol. 10271). https://doi.org/10.1007/978-3-319-58071-5_16 }\end{array}$
\end{tabular}

P29 Kim, Y. (2017). The effect of process management on different types of innovations: An analytical modeling approach. European Journal of Operational Research, 262(2), 771-779. https://doi.org/10.1016/j.ejor.2017.03.064

P30 Ohlsson, J., Han, S., and Bouwman, H. (2017). The prioritization and categorization method (PCM) process evaluation at Ericsson: a case study. Business Process Management Journal, 23(2), 377-398. https:/ / doi.org/10.1108/BPMJ-07-2016-0136

P31 Santos, H., and Alves, C. (2018). Exploring the Ambidextrous Analysis of Business Processes: A Design Science. In ICEIS 2017 (pp. 543-566). Springer International Publishing. https:/ / doi.org/10.1007/978-3-319-93375-7

Ardito, L., Besson, E., Petruzzelli, A. M., and Gregori, G. L. (2018). The influence of
P32 innovations on ambidexterity performance. Business Process Management Journal. https:/ / doi.org/10.1108/BPMJ-11-2017-0306

Baiyere, A., Tapanainen, T., and Salmela, H. (2018). Digital Transformation-Role of Agility in
P33 Twenty-fourth Americas Conference on Information Systems, New Orleans, 2018. Retrieved from https: / / aisel.aisnet.org/cgi/viewcontent.cgi?article=1287\&context=amcis2018

Choudhary, P., Mital, M., Pani, A. K., Papa, A., and Vicentini, F. (2018). Impact of enterprise mobile system

P34 implementation on organizational ambidexterity mediated through BPM customizability. Business Process Management Journal. https://doi.org/10.1108/BPMJ-07-2017-0209

Fain, N., Wagner, B., and Kay, N. (2018). Driving innovation through ambidextrous service provision
P35 products in manufacturing contexts. Technological Forecasting and Social Change, 130(April 2017), 3-13. https://doi.org/10.1016/j.techfore.2017.05.013

P36 Ferraris, A., Monge, F., and Mueller, J. (2018). Ambidextrous IT capabilities and business process performance: an empirical analysis. Business Process Management Journal. https:/ / doi.org/10.1108/BPMJ-07-2017-0201

Festa, G., Safraou, I., Cuomo, M. T., and Ludovico Solima. (2018). Big data for big pharma: Harmonizing business

P37 process management to enhance ambidexterity. Business Process Management Journal. https: / / doi.org/10.1108/BPMJ-10-2017-0272

P38 Gastaldi, L., Appio, F. P., Corso, M., and Pistorio, A. (2018). Managing the exploration-exploitation paradox in healthcare. Business Process Management Journal. https:/ / doi.org/10.1108/BPMJ-04-2017-0092

Giacosa, E., Mazzoleni, A., and Usai, A. (2018). Business Process Management (BPM): How complementary BPM P39 capabilities can build an ambidextrous state in business process activities of family firms. Business Process Management Journal. https:/ / doi.org/10.1108/BPMJ-07-2017-0211

P40 Heckmann, C., and Maedche, A. (2018). IT ambidexterity for business processes: the importance of balance. Business Process Management Journal, 24(4), 862-881. https: / / doi.org/10.1108/BPMJ-10-2016-0214

P41 Lenning, J. (2018). Auditing of explorative processes. Total Quality Management and Business Excellence, 29(9-10), 1185-1199. https: / / doi.org/10.1080/14783363.2018.1487605

Lindskog, C. (2018). Exploitation and Exploration in Business Process Management-An exploratory paper. In 17th

P42 International Conference on Perspectives in Business Informatics Research, Stockholm. Retrieved from http:/ / ceur-ws.org/Vol-2218/paper41.pdf

P43 Luger, J., Raisch, S., and Schimmer, M. (2018). Dynamic Balancing of Exploration and Exploitation: The Contingent Benefits of Ambidexterity. Organization Science, 29(3), 449-470. https: / / doi.org/10.1287/orsc.2017.1189

Miglietta, N., Battisti, E., Carayannis, E., and Salvi, A. (2018). Capital structure and business proce
P44 evidence from ambidextrous organizations. Business Process Management Journal, 24(5), 1255-1270. https:/ / doi.org/10.1108/BPMJ-07-2017-0214 


\begin{tabular}{|c|c|}
\hline P45 & $\begin{array}{l}\text { Raisch, S., Hargrave, T. J., and Van De Ven, A. H. (2018). The Learning Spiral: A Process Perspective on Paradox. Journal } \\
\text { of Management Studies. https:/ / doi.org/10.1111/joms.12397 }\end{array}$ \\
\hline P46 & $\begin{array}{l}\text { Rialti, R., Marzi, G., Silic, M., and Ciappei, C. (2018). Ambidextrous organization and agility in big data era-the role of } \\
\text { business process management systems. Business Process Management Journal. } \\
\text { https:/ / doi.org/10.1108/BPMJ-07-2017-0210 }\end{array}$ \\
\hline P47 & $\begin{array}{l}\text { Röglinger, M., Schwindenhammer, L., and Stelzl, K. (2018). How to Put Organizational Ambidexterity into } \\
\text { Practice-Towards a Maturity Model. In 16th International Conference on Business Process Management. Retrieved from } \\
\text { www.fim-rc.de }\end{array}$ \\
\hline P48 & $\begin{array}{l}\text { Schniederjans, D. G. (2018). Business process innovation on quality and supply chains. Business Process Management } \\
\text { Journal, 24(3), 635-651. https:/ / doi.org/10.1108/BPMJ-04-2016-0088 }\end{array}$ \\
\hline P49 & $\begin{array}{l}\text { Sharma, S. O., and Martin, A. (2018). Re-thinking and re-operationalizing product innovation capability: A review, } \\
\text { critique and extension of dynamic capability view using theoretical triangulation. European Business Review, 30(4), } \\
\text { 374-397. https:/ / doi.org /10.1108/EBR-07-2016-0087 }\end{array}$ \\
\hline P50 & $\begin{array}{l}\text { Tinoco, J. (2018). Innovation Ambidexterity and the Three-Legged Stool: The Value of Business Processes. Graziadio } \\
\text { Business Review, 21(1). Retrieved from } \\
\text { https://gbr.pepperdine.edu/2018/07/innovation-ambidexterity-and-the-three-legged-stool/ }\end{array}$ \\
\hline P51 & $\begin{array}{l}\text { Asif, M. (2019). Exploring the role of core and infrastructure quality management practices in ambidexterity. Total } \\
\text { Quality Management and Business Excellence, 30(9-10),990-1004. https:/ / doi.org/10.1080/14783363.2017.1344549 }\end{array}$ \\
\hline P52 & $\begin{array}{l}\text { Binci, D., Belisari, S., and Appolloni, A. (2019). BPM and change management An ambidextrous perspective } \\
\text { management. Business Process Management Journal. https://doi.org/10.1108/BPMJ-06-2018-0158 }\end{array}$ \\
\hline P53 & $\begin{array}{l}\text { Cunha, M. P. e., Bednarek, R., and Smith, W. (2019). Integrative ambidexterity: one paradoxical mode of learning. } \\
\text { Learning Organization, 26(4), 425-437. https:/ / doi.org/10.1108/TLO-02-2019-0038 }\end{array}$ \\
\hline P54 & $\begin{array}{l}\text { Dilan, E., and Aydin, M. N. (2019). An Integrated Framework for Examining Innovation Alignment in Organizations. } \\
\text { International Journal of Innovation and Technology Management, 16(4). https:/ / doi.org/10.1142/S0219877019500391 }\end{array}$ \\
\hline P55 & $\begin{array}{l}\text { Dost, M., and Badir, Y. F. (2019). Generation or adoption? The role of social capital. Management Decision, 57(7), } \\
\text { 1457-1471. https:/ / doi.org/10.1108/MD-11-2017-1108 }\end{array}$ \\
\hline P56 & $\begin{array}{l}\text { Gieske, H., George, B., Van Meerkerk, I., and Van Buuren, A. (2019). Innovating and optimizing in public organizations: } \\
\text { does more become less? Public Management Review. https:/ / doi.org/10.1080/14719037.2019.1588356 }\end{array}$ \\
\hline P57 & $\begin{array}{l}\text { Heracleous, L., Yniguez, C., and Gonzalez, S. A. (2019). Ambidexterity as Historically Embedded Process: Evidence } \\
\text { From NASA, } 1958 \text { to 2016. Journal of Applied Behavioral Science, 55(2), 161-189. } \\
\text { https:/ / doi.org / 10.1177 / } 0021886318812122\end{array}$ \\
\hline P58 & $\begin{array}{l}\text { Lederer, M., Popova, O., and Schmid, P. (2019). Can you see the wood for the trees? Collection and Compilation of } \\
\text { Agility Models for BPM. In S-BPM ONE'19, June 26-28, 2019, Seville, Spain @ @. https://doi.org/10.1145/3329007.3329016 }\end{array}$ \\
\hline P59 & $\begin{array}{l}\text { Michelino, F., Cammarano, A., Celone, A., and Caputo, M. (2019). The Linkage between Sustainability and Innovation } \\
\text { Performance in IT Hardware Sector. Sustainability, 11(16), 4275. https:/ / doi.org/10.3390/su11164275 }\end{array}$ \\
\hline P60 & $\begin{array}{l}\text { Secchi, R., and Camuffo, A. (2019). Lean implementation failures: The role of organizational ambidexterity. International } \\
\text { Journal of Production Economics, 210(May 2017), 145-154. https:// doi.org/10.1016/j.ijpe.2019.01.007 }\end{array}$ \\
\hline P61 & $\begin{array}{l}\text { Kwak, C., Lee, J., and Lee, H. (2019). Do teams need both hands? An analysis of team process ambidexterity and the } \\
\text { enabling role of information technology. International Journal of Information Management. } \\
\text { https:// doi.org/10.1016/j.ijinfomgt.2019.11.006 }\end{array}$ \\
\hline P62 & $\begin{array}{l}\text { Grisold, T., Gross, S., Röglinger, M., Stelzl, K., and Brocke, J. (2019). Exploring Explorative BPM-Setting the Ground for } \\
\text { Future Related Fields and Agendas. 17th International COnference BPM2019 Vienna, Austria, September 1-6, } 2019 \\
\text { Proceedings, 1(11675), 1-9. https:/ / doi.org/10.1007/978-3-030-26619-6 }\end{array}$ \\
\hline P63 & $\begin{array}{l}\text { Tai, J. C. F., Wang, E. T. G., and Wang, K. (2019). A Model of Coaligned Digital Innovations: The Roles of Flexible IT } \\
\text { Infrastructure and Ambidextrous IS Process Innovations. Retrieved from } \\
\text { http:/ / www.pacis2019.org/wd/Submissions/PACIS2019_paper_463.pdf }\end{array}$ \\
\hline P64 & $\begin{array}{l}\text { Badakhshan, P., Conboy, K., Grisold, T., and vom Brocke, J. (2019). Agile business process management: A systematic } \\
\text { literature review and an integrated framework. Business Process Management Journal, 26(6), 1505-1523. } \\
\text { https:/ / doi.org/10.1108/BPMJ-12-2018-0347 }\end{array}$ \\
\hline P65 & $\begin{array}{l}\text { Gross, S., Malinova, M., and Mendling, J. (2019). Navigating Through the Maze of Business Process Change Methods. In } \\
\text { Proceedings of the 52nd Hawaii International Conference on System Sciences. https: / / doi.org/10.24251/hicss.2019.754 }\end{array}$ \\
\hline
\end{tabular}




\begin{tabular}{|c|c|}
\hline P66 & $\begin{array}{l}\text { Mendling, J., and Recker, J. (2020). Building a Complementary Agenda for Business Process Management and Digital } \\
\text { Innovation. European Journal for Information Systems. Retrieved from } \\
\text { https://www.researchgate.net/profile/Jan_Recker/publication/340528277_Building_a_Complementary_Agenda_- } \\
\text { for_Business_Process_Management_and_Digital_Innovation/links/5e8ef63a299bf1307989f40c/Building-a- } \\
\text { Complementary-Agenda-for-Business-Process-Management-and }\end{array}$ \\
\hline P67 & $\begin{array}{l}\text { Stelz, K. (2020). Organizational Ambidexterity_Exploring and Exploiting the Role of Business Process and Project Portfolio } \\
\text { Management. }\end{array}$ \\
\hline P68 & $\begin{array}{l}\text { Grisold, T. (2020). Teaching the Five-Diamond Method for Explorative BPM Class Notes: Teaching the Five-Diamond } \\
\text { Method for Explorative BPM. Www.Bptrends.Com I, (November). }\end{array}$ \\
\hline P69 & $\begin{array}{l}\text { Stelzl, K., Röglinger, M., and Wyrtki, K. (2020). Building an ambidextrous organization: a maturity model for } \\
\text { organizational ambidexterity. Business Research. https:// doi.org/10.1007/s40685-020-00117-x }\end{array}$ \\
\hline P70 & $\begin{array}{l}\text { Gross, S., Stelzl, K., Grisold, T., Mendling, J., Röglinger, M., and Brocke, J. vom. (2020). The Business Process Design } \\
\text { Space for Exploring Process Redesign Alternatives. Business Process Management Journal. Retrieved from } \\
\text { https:/ / epub.wu.ac.at/7830/1/BusinessProcessDesignSpaceforExploringProcessRedesignAlternatives.pdf }\end{array}$ \\
\hline P71 & $\begin{array}{l}\text { Rosemann, M. (2020). Explorative Process Design Patterns. In Proceedings of the International Conference on Business } \\
\text { Process Management: BPM2020. Retrieved from https://eprints.qut.edu.au/201691/8/BPM_2020_Revised_Version.pdf }\end{array}$ \\
\hline
\end{tabular}

\section{References}

1. Sebastian, I.M.; Mocker, M.; Ross, J.W.; Moloney, K.G.; Beath, C.; Fonstad, N.O. How Big Old Companies Navigate Digital Transformation. MIS Q. Exec. 2017, 16, 197-213.

2. Van Looy, A. On the Synergies between Business Process Management and Digital Innovation; Springer: Cham, Switzerland, 2018; pp. 359-375.

3. Rosemann, M. Proposals for future BPM research directions. Lect. Notes Bus. Inf. Process 2014, 181, 1-15. [CrossRef]

4. Couckuyt, D.; Van Looy, A. Green BPM as a business-oriented discipline: A systematic mapping study and research agenda. Sustainability 2019, 11, 4200. [CrossRef]

5. Stolze, C.; Semmler, G.; Thomas, O. Sustainability in Business Process Management Research-A Literature Review; AMCIS 2012 Proceedings: Seattle, WA, USA, 2012.

6. Dumas, M.; la Rosa, M. Fundamentals of Business Process Management; Springer: Heidelberg, Germany, 2013.

7. Benner, M.J.; Tushman, M.L. Exploration, exploitation and process management: The productivity dilemma revisited. Acad. Manag. J. 2003, 28, 238-256.

8. Schmiedel, T.; Brocke, J.V. Business Process Management: Potentials and Challenges of Driving Innovation; Springer: Cham, Switzerland, 2015; pp. 3-15.

9. Del Giudice, M.; Soto-Acosta, P.; Carayannis, E.; Scuotto, V. Emerging perspectives on business process management (BPM): IT-based processes and ambidextrous organizations, theory and practice. Bus. Process Manag. J. 2018, 24, 1070-1076. [CrossRef]

10. Helbin, T.; Van Looy, A. Business process ambidexterity and its impact on business-it alignment. A systematic literature review. In Proceedings of the International Conference on Research Challenges in Information Science, Brussels, Belgium, 29-31 May 2019.

11. Boell, S.K.; Cecez-Kecmanovic, D. On being 'systematic' in literature reviews in IS. J. Inf. Technol. 2015, 30, 161-173. [CrossRef]

12. O'Reilly, C.A.; Tushman, M.L. Organizational Ambidexterity: Past, Present and Future Academy of Management Perspectives. Acad. Manag. Perspect. 2013, 27, 324-338. [CrossRef]

13. Lavie, D.; Stettner, U.; Tushman, M.L. Exploration and Exploitation Within and Across Organizations. Acad. Manag. Ann. 2010, 4 1941-6067. [CrossRef]

14. Raisch, S.; Birkinshaw, J. Organizational ambidexterity: Antecedents, outcomes, and moderators. J. Manag. 2008, 34, 375-409. [CrossRef]

15. Gibson, C.; Birkinshaw, J. Antecedents, consequences, and mediating: Role of organizational ambidexterity. Acad. Manag. J. 2004, 47, 209-226.

16. He, Z.-L.; Wong, P.-K. Exploration vs. Exploitation: An Empirical Test of the Ambidexterity Hypothesis. Organ. Sci. 2004, 15, 481-494. [CrossRef]

17. Birkinshaw, J. Building ambidexterity into an organization. MIT Sloan Manag. Rev. 2004, 45, 47-55.

18. Andriopoulos, C.; Lewis, M.W. Exploitation-Exploration Tensions and Organizational Ambidexterity: Managing Paradoxes of Innovation. Organ. Sci. 2009, 20, 686-717. [CrossRef]

19. Farjoun, M. Contradictions, Dialectics, and Paradoxes. In SAGE Handbook of Process Organization Studies; SAGE Publications Ltd.: London, UK, 2021; pp. 87-109.

20. March, J.G. Exploration and Exploitation in Organizational Learning. Organ. Sci. 1991, 2, 71-87. [CrossRef]

21. Cohen, W.M.; Levinthal, D.A. Absorptive Capacity: A New Perspective on Learning and Innovation. Adm. Sci. Q. 1990, 35, 128-152. [CrossRef] 
22. O'Reilly, C.A.; Tushman, M.L. Ambidexterity as a dynamic capability: Resolving the innovator's dilemma. Res. Organ. Behav. 2008, 28, 185-206. [CrossRef]

23. Danneels, E. Trying to become a different type of company: Dynamic capability at Smith Corona. Strateg. Manag. J. 2010, 31, 1-43. [CrossRef]

24. Eisenhardt, K.M.; Martin, J.A. Dynamic capabilities: What are they? Strateg. Manag. J. 2000, 21, 1105-1121. [CrossRef]

25. Cao, Q.; Gedajlovic, E.; Zhang, H. Unpacking Organizational Ambidexterity: Dimensions, Contingencies, and Synergistic Effects. Organ. Sci. 2009, 20, 781-796. [CrossRef]

26. Werder, K.; Heckmann, C. Ambidexterity in Information Systems Research: Overview of Conceptualizations, Antecedents, and Outcomes. J. Inf. Technol. Theory Appl. 2019, 20, 28-52.

27. Van Looy, A.; de Backer, M.; Poels, G. A conceptual framework and classification of capability areas for business process maturity. Enterp. Inf. Syst. 2014, 8, 188-224. [CrossRef]

28. Ortbach, K.; Plattfaut, R.; Pöppelbuß, J.; Niehaves, B. A dynamic capability-based framework for Business Process Management: Theorizing and empirical application. In Proceedings of the 2012 45th Hawaii International Conference on System Sciences, Maui, HI, USA, 4-7 January 2012; pp. 4287-4296.

29. Brocke, J.V.; Recker, J.; Trkman, P.; Mertens, W.; Viaene, S. Ten Principles of Good Business Process Management. Bus. Process Manag. J. 2014, 20, 530-548. [CrossRef]

30. Van Looy, A. A Quantitative Study of the Link Between Business Process Management and Digital Innovation. BPM Forum 2017, $329,177-192$.

31. Van Looy, A. A quantitative and qualitative study of the link between business process management and digital innovation. Inf. Manag. 2021, 58, 103413. [CrossRef]

32. Harmon, P. The Scope and Evolution of Business Process Management. In Handbook on Business Process Management 1; Springer: Berlin/Heidelberg, Germany, 2010; pp. 37-81.

33. Hill, C.W.L.; Rothaermel, F.T. The Performance of Incumbent Firms in the Face of Radical Technological Innovation. Acad. Manag. Rev. 2003, 28, 257-274. [CrossRef]

34. Mendling, J.; Decker, G.; Germany, S.; Hull, R.; Reijers, H.A. How do Machine Learning, Robotic Process Automation, and Blockchains Affect the Human Factor in Business Process Management? Commun. Assoc. Inf. Syst. 2018, 43, 1-23. [CrossRef]

35. Benner, M.J.; Tushman, M.L. Process Management and Technological Innovation: A Longitudinal Study of the Photography and Paint Industries. Adm. Sci. Q. 2002, 47, 676-706. [CrossRef]

36. Kitchenham, B.; Charters, S.; Budgen, D.; Brereton, P. Performing systematic literature reviews in software engineering. In Proceedings of the 28th International Conference on Software Engineering-ICSE '06, Shanghai, China, 20-28 May 2006.

37. Okoli, C.; Schabram, K. Working Papers on Information Systems A Guide to Conducting a Systematic Literature Review of Information Systems Research. Work. Pap. Inf. Syst. 2010, 10, 1-47.

38. Strauss, C.L. The Savage Mind; University of Chicago Press: Chicago, IL, USA, 1962. 